\title{
Culture of Safety: Impact on Improvement in Infection Prevention Process and Outcomes
}

\author{
Barbara I. Braun ${ }^{1}$ (D) Salome O. Chitavi ${ }^{1} \cdot$ Hiroyuki Suzuki $^{2} \cdot$ Caroline A. Soyemi $^{3} \cdot$ Mireia Puig-Asensio $^{4,5}$ (D)
}

Accepted: 27 October 2020 / Published online: 2 December 2020

(C) Springer Science+Business Media, LLC, part of Springer Nature 2020

\begin{abstract}
Purpose Safety culture is known to be related to a wide range of outcomes, and measurement of safety culture is now required for many hospitals in the U.S.A. In previous reviews, the association with outcomes has been limited by the research design and strength of the evidence. The goal of this review was to examine recent literature on the relationship between safety culture and infection prevention and control-related (IPC) processes and healthcare-associated infections (HAIs) in U.S. healthcare organizations. We also sought to quantitatively characterize the challenges to empirically establishing these relationships and limitations of current research.

Recent Findings A PubMed search for U.S. articles published 2009-2019 on the topics of infection prevention, HAIs, and safety culture yielded 448 abstracts. After screening, 55 articles were abstracted for information on purpose, measurement, analysis, and conclusions drawn about the role of safety culture in the outcome. Approximately $1 / 2$ were quality improvement (QI) initiatives and $1 / 2$ were research studies. Overall, $51(92.7 \%)$ concluded there was an association between safety culture and IPC processes or HAIs. However, only 39 studies measured safety culture and 26 statistically analyzed safety culture data for associations. Though fewer QI initiatives analyzed associations, a higher proportion concluded an association exists than among research studies.

Summary Despite limited empirical evidence and methodologic challenges to establishing associations, most articles supported a positive relationship between safety culture, improvement in IPC processes, and decreases in HAIs. Authors frequently reported experiencing improvements in safety culture when not directly measured. The findings suggest that associations between improvement and safety culture may be bi-directional such that positive safety culture contributes to successful interventions and implementing effective interventions drives improvements in culture. Greater attention to article purpose, design, and analysis is needed to confirm these presumptive relationships.
\end{abstract}

Keywords Safety culture $\cdot$ Infection prevention and control $\cdot$ Healthcare-associated infections $\cdot$ Organizational culture

This article is part of the Topical Collection on Healthcare Associated Infections

Barbara I. Braun

bbraun@jointcommission.org

Salome O. Chitavi

schitavi@jointcommission.org

Hiroyuki Suzuki

hiroyuki-suzuki@uiowa.edu

Caroline A. Soyemi

carolinesoyemi@yahoo.com

Mireia Puig-Asensio

mireia-puigasensio@uiowa.edu
Department of Research, The Joint Commission, Oakbrook Terrace, IL, USA

2 Department of Internal Medicine - Infectious Diseases, Roy J. and Lucille A. Carver College of Medicine, University of Iowa, Iowa City, IA, USA

3 Neihoff School of Nursing, Loyola University Chicago, Chicago, IL, USA

4 Department of Internal Medicine, Carver College of Medicine, Iowa City, IA, USA

5 Department of Infectious Diseases, Hospital Universitari de Bellvitge: L'Hospitalet de Llobregat, Barcelona, Catalunya, Spain 


\section{Introduction}

\section{Why Understand the Relationship Between Safety Culture, Infection Prevention and Control, and Healthcare-Associated Infections}

Given the major impact of healthcare-associated infections (HAI) on morbidity, mortality, and costs of care, there have been many efforts to prevent HAIs by improving infection prevention and control (IPC) practices in the last 20 years. These include establishing the U.S. Department of Health and Human Services (DHHS) National HAI Action Plan, required reporting of hospital HAIs to the Centers for Disease Control and Prevention (CDC) National Healthcare Safety Network (NHSN), state-based HAI prevention activities, Joint Commission National Patient Safety Goals specific to HAIs, public reporting of HAIs in Medicare data, and U.S. Agency for Healthcare Research and Quality (AHRQ) healthcareassociated infections program [1-8]. While substantial progress has been made, it remains difficult to ascertain the impact of individual initiatives on overall progress $[9,10]$.

Safety culture is one factor considered in recent years to have a major impact on patient outcomes including HAIs [11, 12]. The often-stated phrase "culture eats strategy for lunch (and breakfast and dinner)" exemplifies its presumed importance $[13,14]$. Several initiatives are underway to improve culture related to patient and staff safety within healthcare settings [15-17]. Culture is also closely related to leadership [18-20].

\section{What Is Safety Culture}

Safety culture has been defined as the product of individual and group beliefs, values, attitudes, perceptions, competencies, and patterns of behavior that determine the organization's commitment to quality and patient safety [21]. According to AHRQ, a culture of safety encompasses four key principles:

- Acknowledgment of the high-risk nature of an organization's activities and the determination to achieve consistently safe operations

- A blame-free environment where individuals can report errors or near misses without fear of reprimand or punishment

- Encouragement of collaboration across ranks and disciplines to seek solutions to patient safety problems

- Organizational commitment of resources to address safety concerns [22].

The terms safety culture, safety climate, and organizational culture are conceptually distinct but often used interchangeably. Organizational culture refers to the deeply embedded norms, values, beliefs, and assumptions shared by members of an organization [23]. These elements evolve over time and are difficult to change. Organizational climate, by contrast, refers to the shared perceptions at a given point in time regarding organizational practices such as decision-making, advancement opportunities, and so on. These are more amenable to change. Safety climate is a subset (or microclimate) of overall organizational climate that focuses on people's perceptions about the extent to which the organization values safety (for workers, patients, and/or the environment) [12, 24-26]. In this article, we use the broader term safety culture to include studies addressing safety climate and organizational climate when appropriate.

\section{Why Safety Culture Should Be Measured}

Healthcare quality oversight bodies and related groups recommend organizations address safety culture. Organizations accredited by The Joint Commission are expected to ensure that leaders maintain a culture of safety and regularly evaluate the culture using valid and reliable tools [27]. The National Quality Forum recommended measurement of culture in its Safe Practices for Healthcare [28]. Similarly, The Leapfrog Group, which conducts hospital surveys related to quality and safety, incorporates measurement and use of safety culture data in its ratings of hospital performance [29]. AHRQ also recommends yearly measurement of safety culture as one of its ten patient safety tips for hospitals [30]. The 2020 Institute for Healthcare Improvement (IHI) National Patient Safety Action Plan recommends assessing safety culture at least every 2 years [31].

The mechanism by which safety culture can influence the IPC process and HAIs has been described in several conceptual models, many of which derive from Donabedian's model of structure, process, and outcome [25, 32]. Figure 1 presents a simplified conceptual model for the relationship between safety culture, IPC processes, and HAI rates derived from the previous work. Essentially, the input of individual characteristics (both patients and staff) interacts with organizational structural factors (such as staffing, equipment) and culture of safety (impacted by leadership) which then influences the process of care (e.g., adherence to recommended IPC processes such as contact precautions and hand hygiene). These inputs in turn collectively affect the outcome of HAIs for both patients and staff.

There is evidence from the Comprehensive Unit-based Safety Program (CUSP) initiative that driving large-scale improvement in IPC practices and HAI rates requires multifaceted strategies that address clinician knowledge attitudes and behaviors as well as organizational factors. The CUSP implementation framework includes engagement of frontline clinicians and institutional senior leadership; education in the science of safety; assessment of safety culture and infection 


\section{Individual/Personal Factors}

\section{Organizational} Factors

\section{IPGrelated \\ IPGrelated
Outcomes}

Patient and Staff Characteristics

(e.g. severity of illness, staff knowledge and beliefs)

\section{Safety Culture}

(e.g. domains of teamwork,

leadership support,

communication etc.)
Adherence to IPC Processes

(e.g. hand hygiene, contact

precautions, bundled interventions)

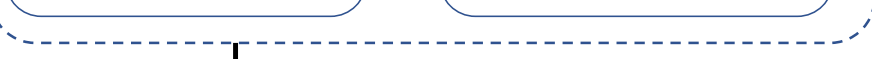

Healthcare-associated infections

(e.g. bloodstream infections, surgical site

infections, occupationally-acquired illnesses)

\section{Adapted from Donabedian 2005 and Stone 2008}

Fig. 1 Conceptual framework for safety culture and infection prevention and control-related (IPC) process and outcomes

control policies and procedures; regional consortia of stakeholders; expert coaching, consultation, and technical assistance; peer support; educational materials, tools, and webinars; data collection and feedback for performance monitoring; and patient and family engagement. Originally demonstrated in the Michigan Keystone Project Collaborative ICU initiative to reduce central line-associated bloodstream infections (CLABSI), AHRQ has supported the implementation and evaluation of the CUSP model nationally and its application to other types of HAIs (e.g., catheter-associated urinary tract infections (CAUTI) and ventilator-associated pneumonia (VAP)) and settings (nursing homes, dialysis) as well as other outcomes [33,34]. Safety culture remains a key component of the CUSP initiatives.

There are additional reasons to understand the relationship between safety culture, IPC process, and HAIs. If a strong relationship exists, one can focus interventions on improving safety culture. In theory, an intervention that improves safety culture could also improve non-IPCrelated outcomes ("lift all boats"). For example, a recent systematic review of 62 high-quality studies by Braithwaite et al. found that positive organizational and workplace cultures were associated with a variety of patient outcomes such as reduced rates of mortality, falls, and HAIs and increased patient satisfaction [35]. Though a discussion of strategies to improve safety culture is beyond the scope of this article, there is little research on the modifiability of culture beyond knowing it to be a slow process and difficult to accomplish [36-39].

Another reason to understand the relationship between safety culture, IPC, and HAIs is to establish the value (or lack thereof) of safety culture measurement and analysis activities. Collecting and analyzing safety culture data can require significant effort, burden, and expense [40, 41]. The evidence base is needed to help justify these efforts.

\section{Research on Safety Culture and Outcomes}

Previous systematic reviews have examined the relationship between safety culture and the IPC process and/or HAIs. These reviews have been generally supportive of the relationship between these factors but are based on limited evidence. One systematic review examined the relationship between patient safety climate and adherence to standard precautions. After excluding intervention studies, Hessels and Larson found only 7 studies eligible for inclusion, all of which were cross-sectional designs [42•]. A recent systematic review by van Buitjene included 20 studies and found $90 \%$ produced supportive evidence for the hypothesis of a link between organizational culture and HAI rates, despite the fact that 8 included studies did not actually measure safety culture [43••]. DeBono synthesized studies on the relationship between organizational culture and behavioral attitudes toward IPC [44*0]. They found that effective IPC relies directly upon the successful interplay of multiple management systems strongly influenced by corporate culture, and that improving organizational culture appears to be a promising albeit challenging target for IPC improvement campaigns, although better-quality studies are urgently needed.

\section{Challenges to Linking Safety Culture, Infection Prevention and Control Activities, and Outcomes}

There are several reasons why establishing a causal relationship between safety culture, IPC processes, and HAIs has been difficult in previous research. Challenges to 


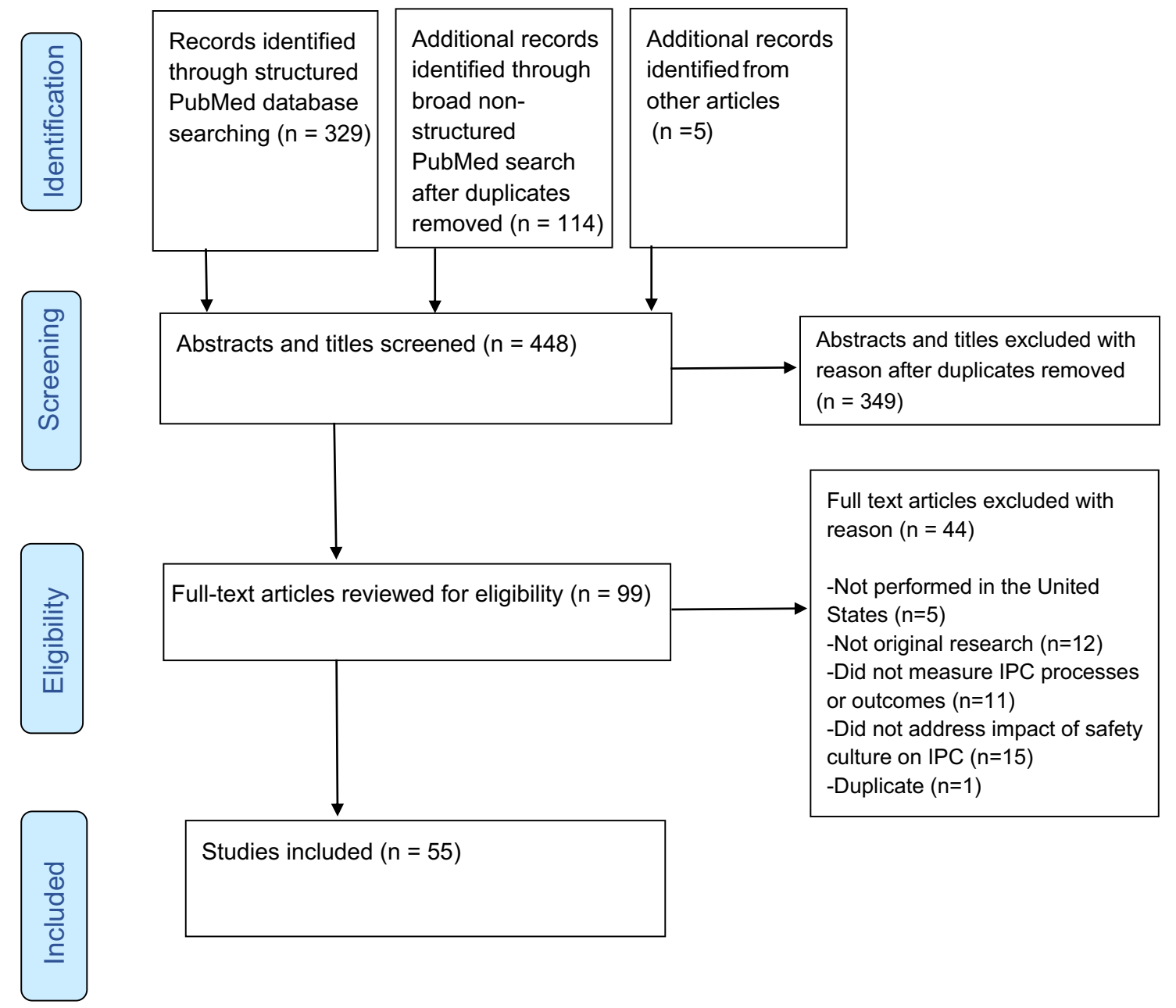

Fig. 2 PRISMA flow diagram for literature review process

measurement and analysis for each of these areas are described below.

\section{Safety Culture}

- Studies that measure safety culture often use different instruments which vary in psychometric properties such as reliability, validity, and sensitivity to change [45].

- Perceptions of safety culture are not necessarily related to actual practice. For example, a qualitative study by Szymczak eloquently describes how the situational complexity of interactions affects both the willingness and ability of staff to "speak up" to prevent an error [46].

- Analyses of safety culture data may be too simplistic. For example, researchers debate whether to aggregate levels of agreement (consensus) within units and domains or to analyze data using dispersion models in which variability, the degree of disagreement among respondents, is more informative [47, 48].

\section{Infection Prevention and Control Practices}

- Measuring adherence to IPC practices is not easy. There is no nationally standardized approach for hand hygiene measurement in the U.S.A., and interpretation of rates is often affected by threats to validity, such as the Hawthorne effect, and insufficient numbers of observations [49]. Measuring adherence to evidence-based care bundles using checklists, while more comprehensive, can be time consuming and variable in approach, timing, and numbers [50].

\section{Healthcare-Associated Infections}

- Measurement of HAIs, though more standardized than IPC, is heavily dependent on time frames and surveillance processes. Some HAIs are more reliable to collect than others [51]. The unit of measurement-ICU level, hospital-wide, single HAI or multiple-also varies.

- Factors that directly influence development of HAIs often differ according to the HAI of interest and are greatly 
affected by patient risk characteristics such as comorbidities [52].

- Establishing attribution for the HAI is challenging. As described by Gardam, during a hospital stay, a patient can be exposed to thousands of different environmental and human contacts that may lead to an infection [37]. While only one exposure may lead to infection, it is nearly impossible to determine which one was responsible.

\section{Directionality and Causation}

- Directionality for cause and effect regarding IPC improvement and safety culture remains to be established. For example, can improving IPC processes result in enhanced safety culture or does improvement in safety culture result in better IPC processes?

- The ability to establish relationships and causality is, of course, affected by the purpose of the initiative as well as the study design [53]. Articles are often based on uncontrolled, pre-post intervention QI projects never intended to be considered research studies [54-56]. However, some consider QI initiatives to be quasi-experimental designs when using pre-post or time series approaches, particularly when there is a control group [57]. While the common goal includes improving care processes and outcomes, QI research is distinct in its focus on broader, generalizable research questions with hypotheses, multiple sites, and advanced statistical analysis [58].

\section{Purpose of This Review}

In previous reviews, the association with outcomes has been limited by the research design and strength of the evidence. Authors rarely distinguished between reports of QI initiatives and research studies or explored safety culture measurement issues. For this review, we examined authors' findings and interpretation of the relationship between safety culture, IPC processes, and HAIs in both QI and research articles. We also sought to quantitatively characterize the variation in measurement of safety culture, the IPC process, and HAIs. Though not intended to be a comprehensive scoping or systematic literature review, we performed a new search of PubMed to identify recent articles in this topic area.

\section{Methods}

\section{Data Sources and Search Strategy}

Two literature searches were performed by medical librarians. A structured literature search of PubMed was performed in
November 2019 for relevant articles across all healthcare settings, published in English language in the past 10 years that included safety culture and infection control process and/or infection control outcomes. To broaden the search of safety culture, we also included terms such as safety climate and organizational culture. Shortly thereafter, a second broad non-structured search was also performed. The unstructured search utilized free text of terms "infection prevention and safety culture" and the "similar articles" function. The first search yielded 329 and the second yielded 114 abstracts and titles. An additional five records were identified from references in other articles. A total of 448 abstracts and titles were retrieved.

\section{Eligibility Criteria, Screening, and Characterization Process}

After de-duplication by the librarians, two researchers screened the 448 titles and abstracts for eligibility. We included studies that measured infection prevention processes or HAIs and also measured safety culture or included an intervention or objective to improve safety culture. We excluded commentaries, editorials, and related articles that were not studies or QI initiatives, and all articles involving healthcare organizations from outside the U.S.A. After 448 abstracts were screened, 99 full text articles were assessed for eligibility for inclusion and a total of 55 articles were included (Fig. 2).

Study data were collected and managed using a standardized data abstraction form in Research Electronic Data Capture (REDCap) electronic data capture tools hosted at the University of Iowa $[59,60]$. REDCap is a secure, webbased software platform designed to support data capture for research studies, providing (1) an intuitive interface for validated data capture; (2) audit trails for tracking data manipulation and export procedures; (3) automated export procedures for seamless data downloads to common statistical packages; and (4) procedures for data integration and interoperability with external sources.

Five researchers were sequentially assigned to abstract information from the 55 articles. Reviewers documented safety culture measurement and domains; conceptual model used, if any; IPC process(s) measured; HAIs measured; studyreported findings and relation to safety culture; and added comments. All articles were also classified by type as being either QI or research; research studies were then categorized by study design as qualitative, cross-sectional, or quasiexperimental.

Each full-text article was reviewed by one researcher. However, when the researcher had doubts regarding the inclusion/exclusion criteria of an article or results were not clear, the article was independently reviewed by a second reviewer. Eighteen articles were reviewed by at least two reviewers. Disagreements between reviewers were discussed 
and resolved by group consensus. Since the review focused exclusively on published articles, it was not considered to be human subject research.

\section{What Does the Research Show}

\section{Settings and Populations}

Of 55 articles, most $(49,89.1 \%)$ were based on initiatives in hospitals, 6 of which focused on pediatric populations and 3 on veterans. Other settings included nursing homes $(n=3)$, dialysis clinics $(n=2)$, and dental offices $(n=1)$. The majority, $36(65.5 \%)$, involved multiple sites and 19 were singlesite studies.

\section{Purpose and Design}

When stratified by type, slightly more than $1 / 2(28,50.9 \%)$ were primarily QI initiatives, four of which were large scale involving more than 100 sites [33,61-63]. The remaining 27 were research articles with the following designs: 17 crosssectional, 6 quasi-experimental, and 4 qualitative.

Thirty-eight articles (69.1\%) included an intervention, 15 of which utilized the CUSP approach.

\section{Safety Culture Measurement}

Articles varied considerably in measuring safety culture with respect to instruments, mode of survey administration, timing relative to an intervention (e.g., baseline only or multiple measurements over time), unit of analysis (e.g., hospital-wide or ICU specific), and respondents (e.g., all staff vs only infection prevention leaders). Overall, 39 (70.9\%) articles measured safety culture with a standardized tool such as the AHRQ Hospital Survey of Patient Safety Culture (HSOPSC) $(n=$ 16) [47, 64-78]; Nursing Home Survey on Patient Safety Culture (NHSPSC) $(n=2)[79,80]$; the Safety Attitudes Questionnaire (SAQ) $(n=9)$ [62, 81-87]; the National Database of Nursing Quality Indicators (NDNQI) $(n=2)$ $[74,88]$; or qualitative methods $(n=4)$. Not all articles mentioned which safety culture domains were assessed, while some only assessed one domain of safety culture (e.g., teamwork) $[78,84]$.

Of the 39 articles, $25(64.1 \%)$ measured safety culture at a single point in time (e.g., baseline) while 14 (35.9\%) measured safety culture multiple times over the study period.

Most measurements occurred at a hospital level, but some were performed at a unit level: ICUs or NICUs $(n=11)$, surgical units $(n=2)$, cardiac surgery unit $(n=1)$, medical wards $(n=1)$, medical unit for the elderly $(n=1)$, and hematooncology unit $(n=1)$. Of note, eight articles reported information from hundreds of ICUs $[47,61-63,69,82,89,90]$ and at least two articles reported data from a wide variety of both ICU and non-ICU units $[63,68]$.

Most respondents to the safety culture assessments were physicians, nurses, and other staff working in the participating units. However, some articles focused exclusively on hospital epidemiologists or infection preventionists (such as [89, 91-93]), nurses (such as $[64,76,94]$ ), or members of a dental hygienist professional association [95].

Research articles measured safety culture more frequently than QI articles. All the 27 research articles measured safety culture compared with less than $1 / 2$ of QI articles (12 of 28).

\section{Outcomes of Interest: IPC Processes of Care and HAls}

Tables 1, 2, and 3 describe which aspects of IPC process were evaluated, what HAIs were measured, and the author's findings and conclusions on the relationship between safety culture and IPCs and/or HAIs.

Table 1 presents 13 articles that address the relationship between safety culture and IPC processes. The IPC processes measured varied and included 4 articles that measured compliance with policies and guidelines ([64, 89, 92, 95]), two that measured compliance with HAI prevention bundles (e.g., CLABSI, daily interruption of sedation, antibiotic prophylaxis, standard precautions) ([83, 96]), and 3 articles that focused on hand hygiene $([81,97,98])$. One article measured aspects of infection control structure [91]. Other process-related measures included willingness to adopt CUSP interventions [82], attitudes and beliefs about a Klebsiella pneumoniae carbapenemase (KPC)-producing Enterobacteriaceae control program [99], and how hospital CLABSI prevention efforts encouraged employees' efforts to speak up and prevent errors [100].

Table 2 presents 20 articles that address the relationship between safety culture and HAIs. There was also substantial heterogeneity in the type of HAIs measured. However, most of them $(n=15,75 \%)$ measured CLABSIs, CAUTIs, VAPs, or SSIs either exclusively or as a combined outcome [47, 61, $66,68-70,77,79,80,86,94,101-104]$. Other HAIs in single articles were colon SSIs [67], hospital-acquired sepsis [65], and $C$. difficile [77], and 3 did not specify the type of HAI measured [71, 84, 85].

Table 3 presents 22 articles that measured both IPC processes and HAIs to address the relationship with safety culture. In this group, most articles $(14,90.9 \%)$ measured process compliance with HAI prevention bundles (e.g., CLABSI, VAP, MRSA screening adherence) $[62,63,72,73,75,87$, $88,90,93,105-109]$ or hand hygiene adherence [110-113] or adherence to policy and guidelines [76, 78, 114]. Regarding HAIs, most $(n=17,81.8 \%)$ measured CLABSIs, CAUTIs, VAPs, or SSIs either exclusively or as a combined outcome $[62,63,72,73,75,76,78,87,88,90,93,105-110,113]$. Of note, $C$. difficile was only explored as an outcome by two [63, 

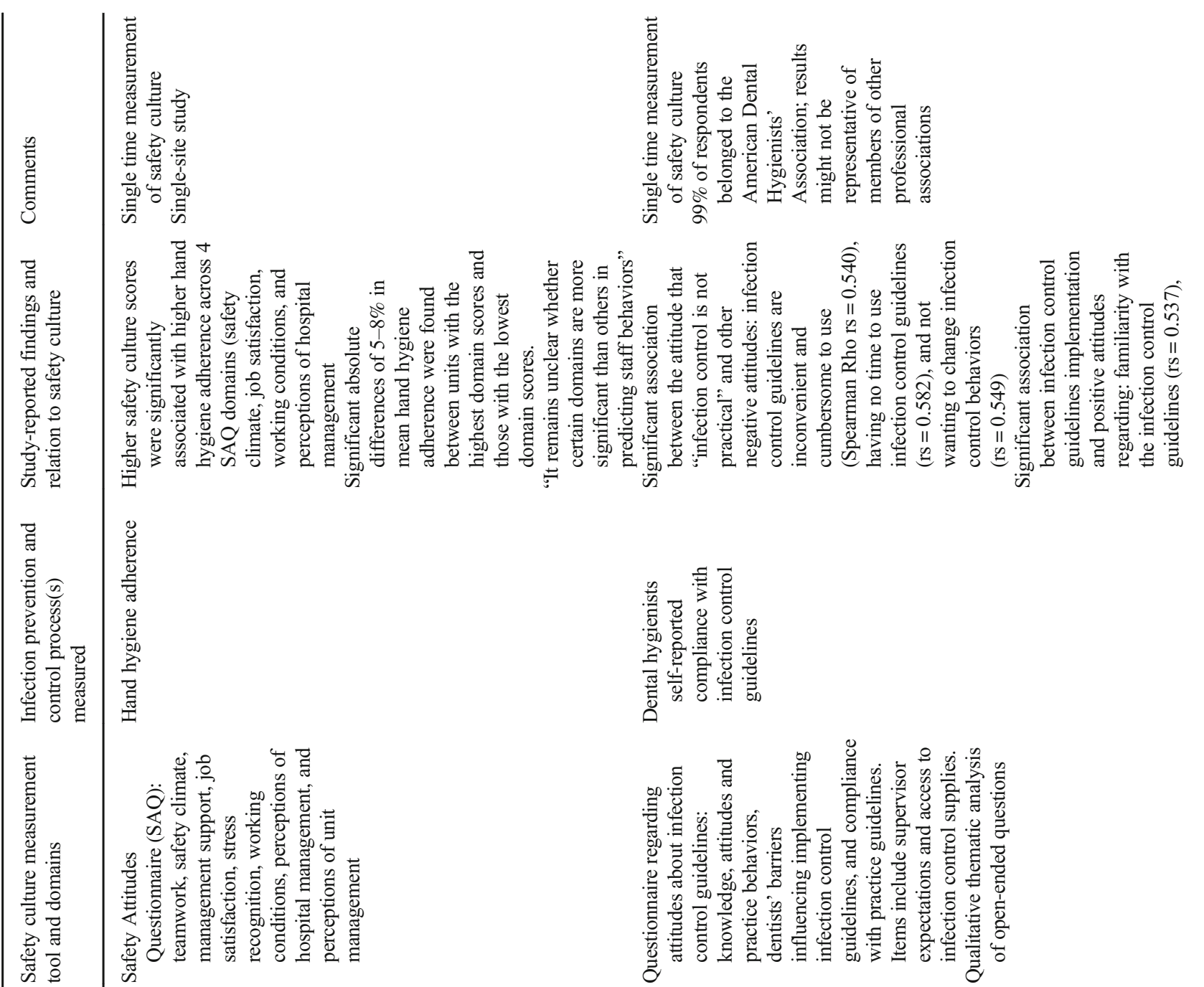

ฉั

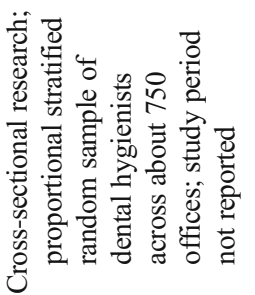

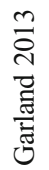




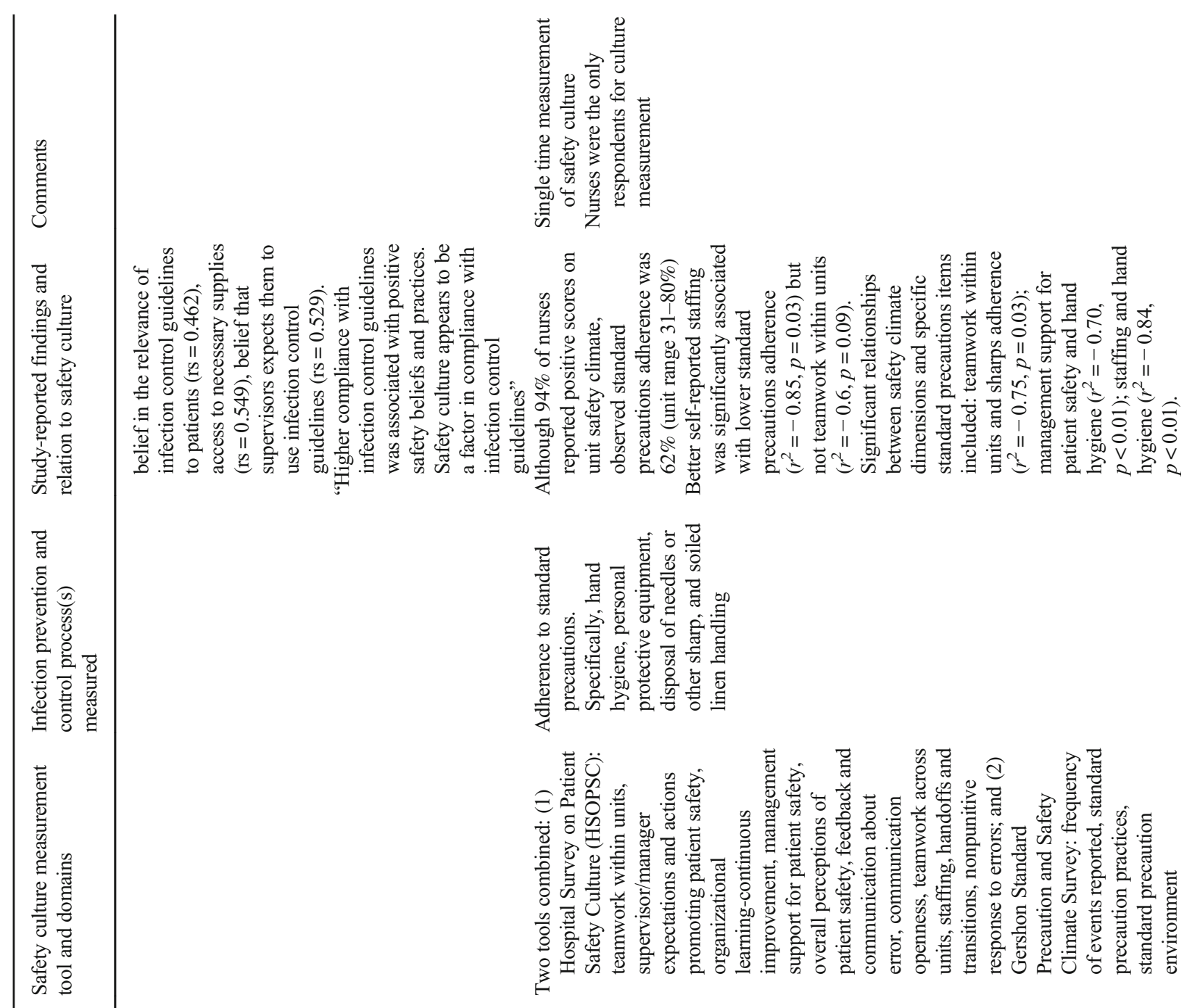

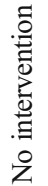

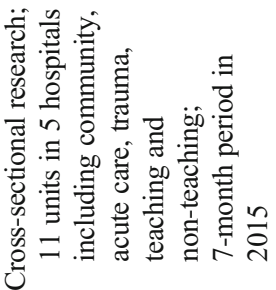

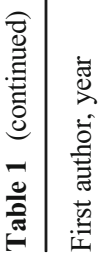

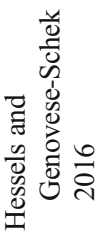




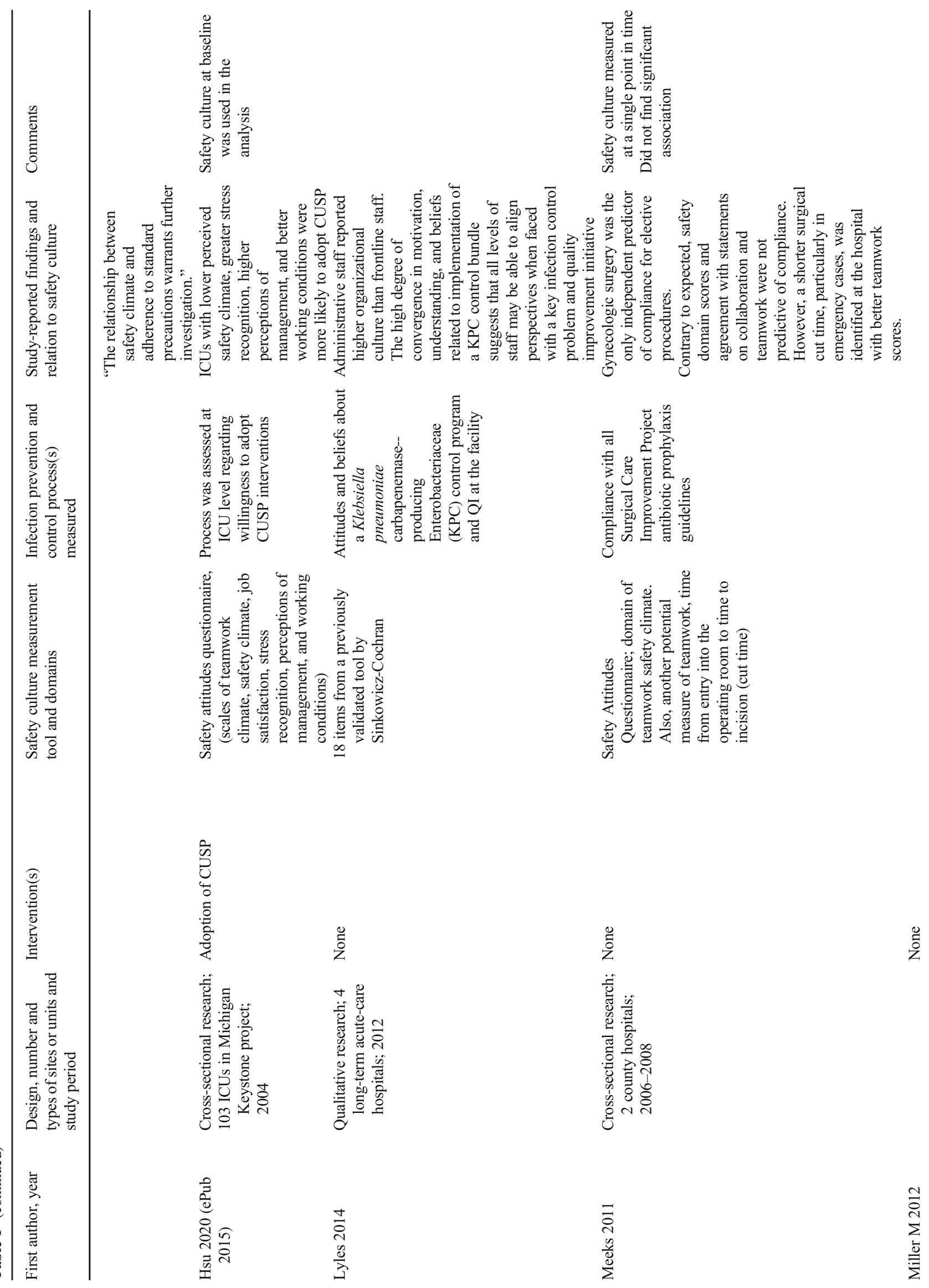




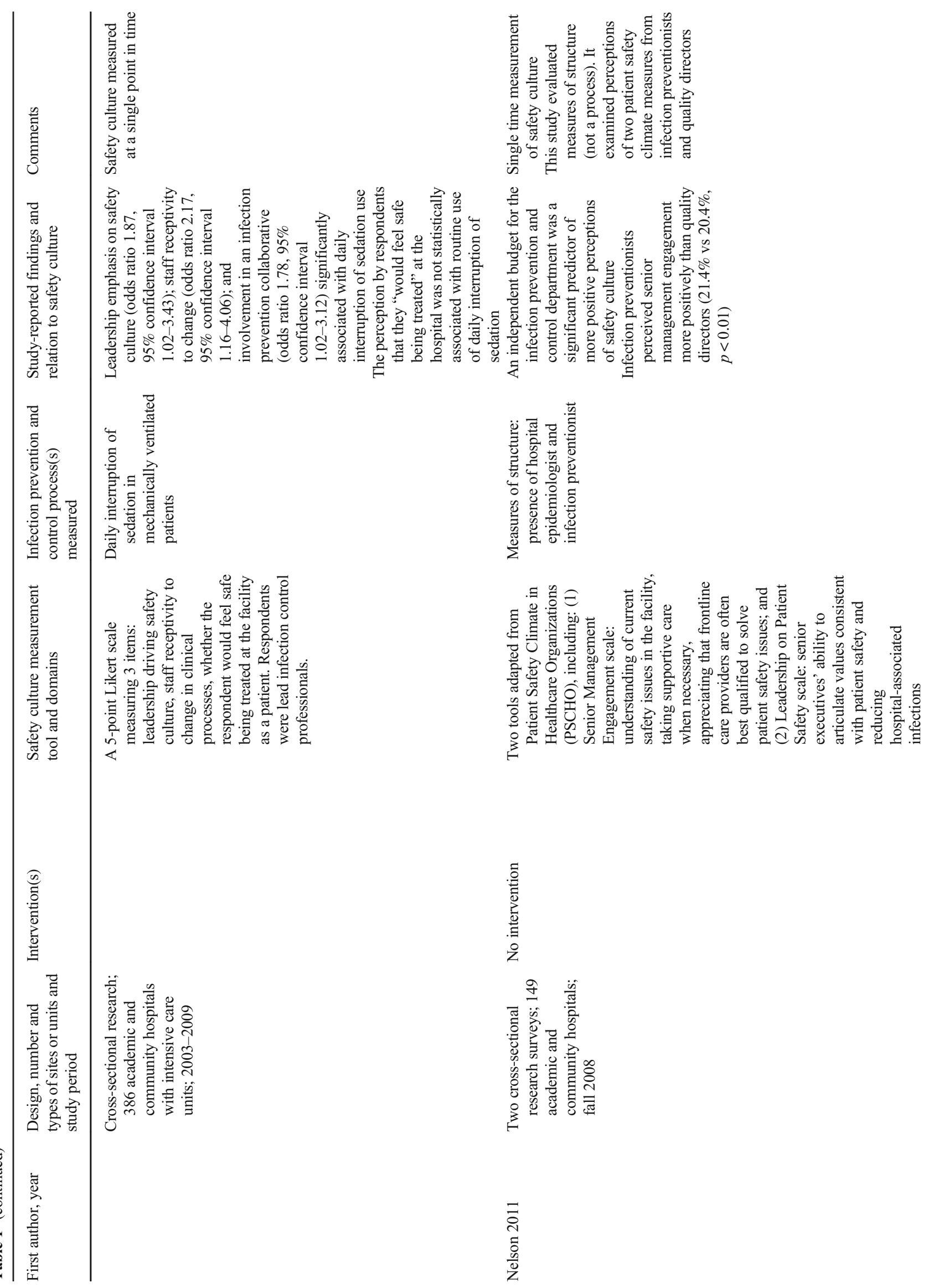




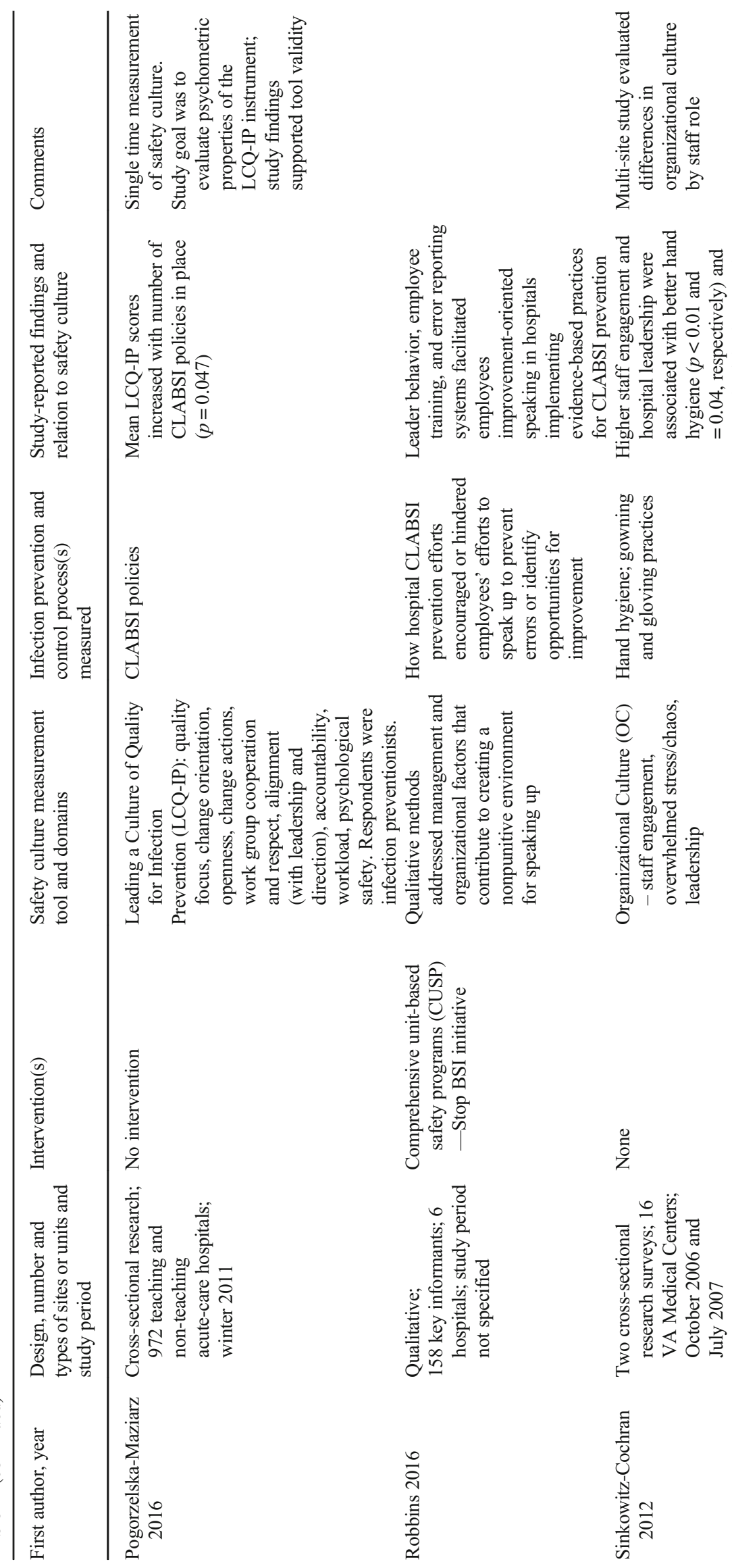




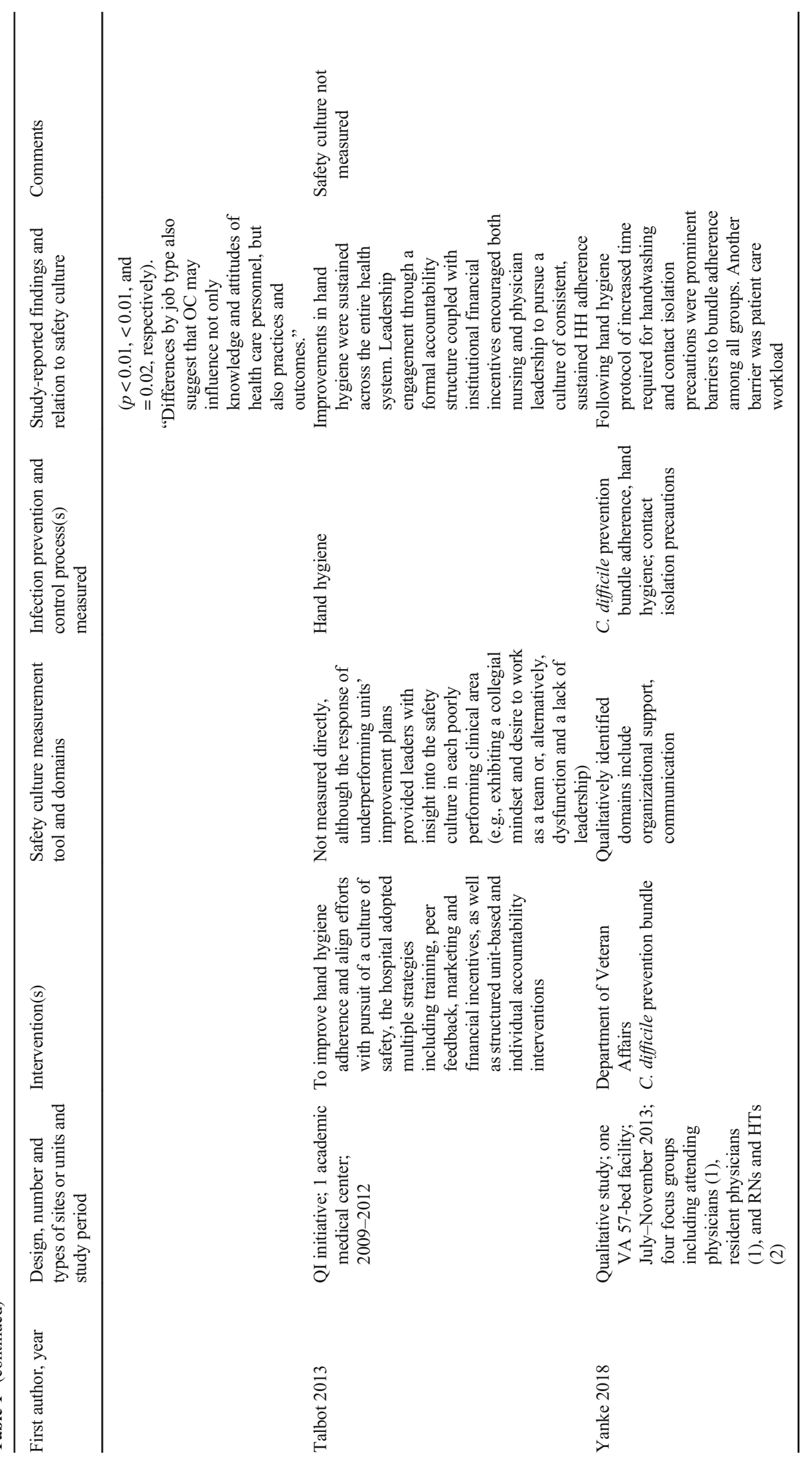




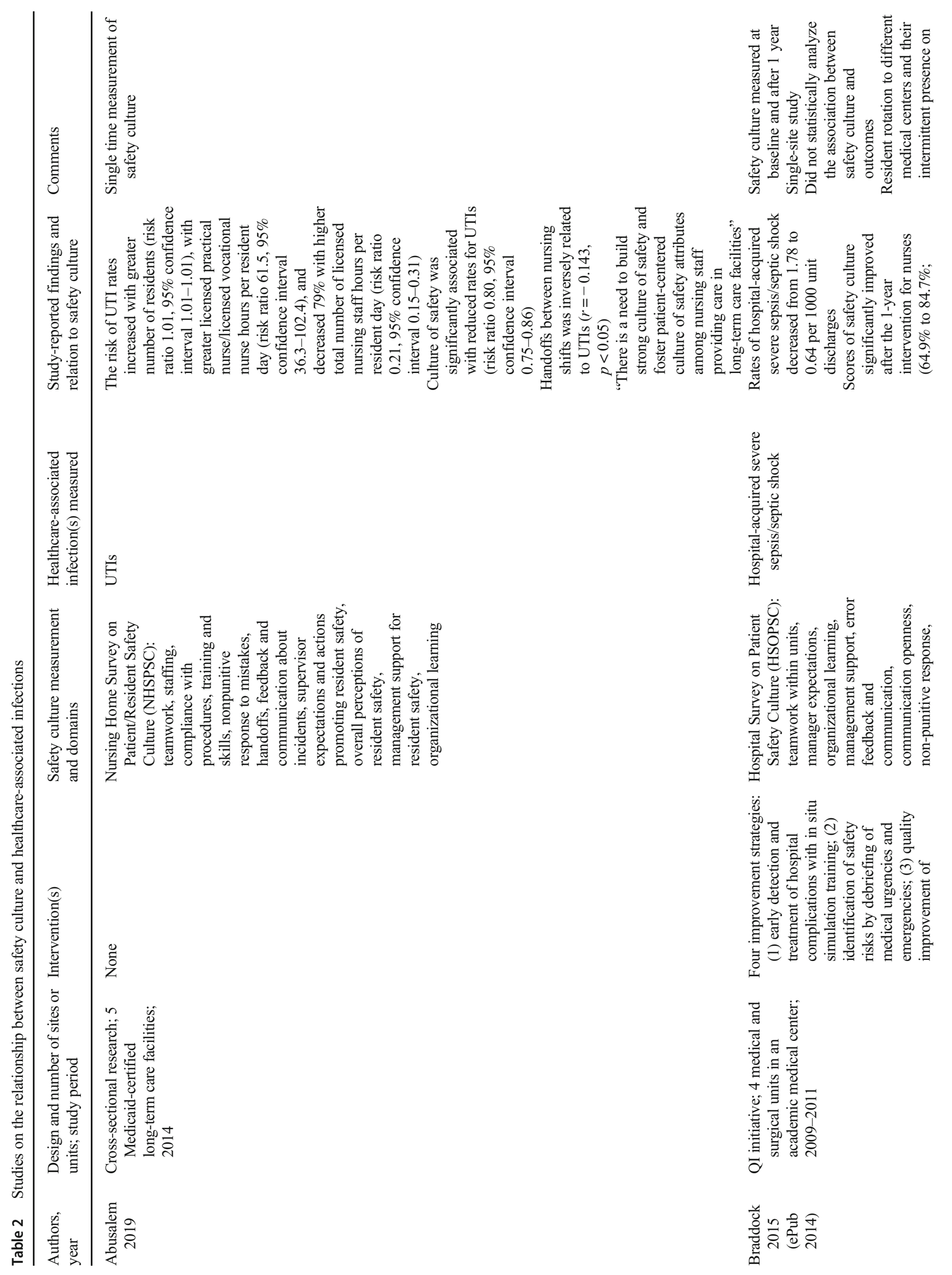




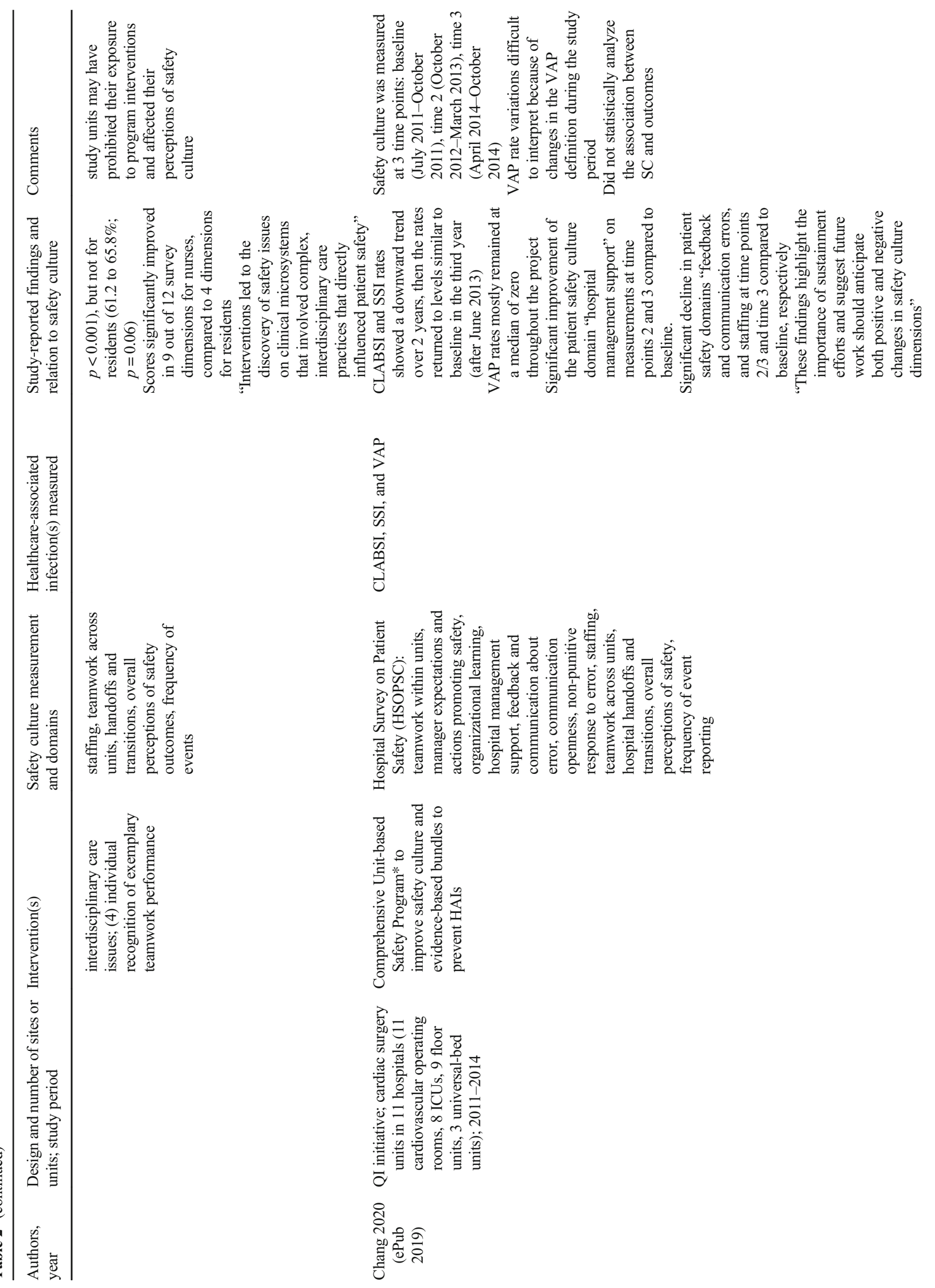




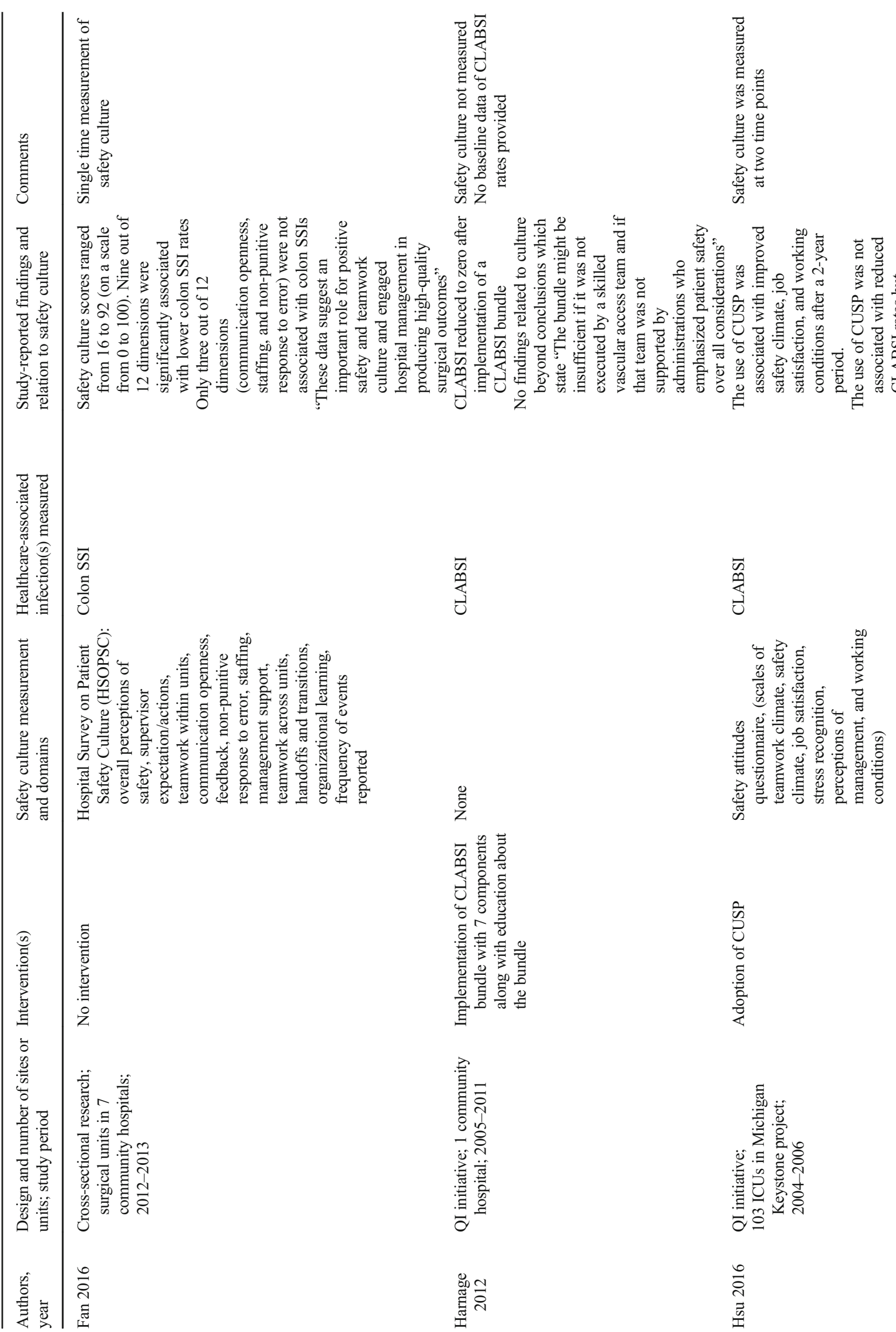




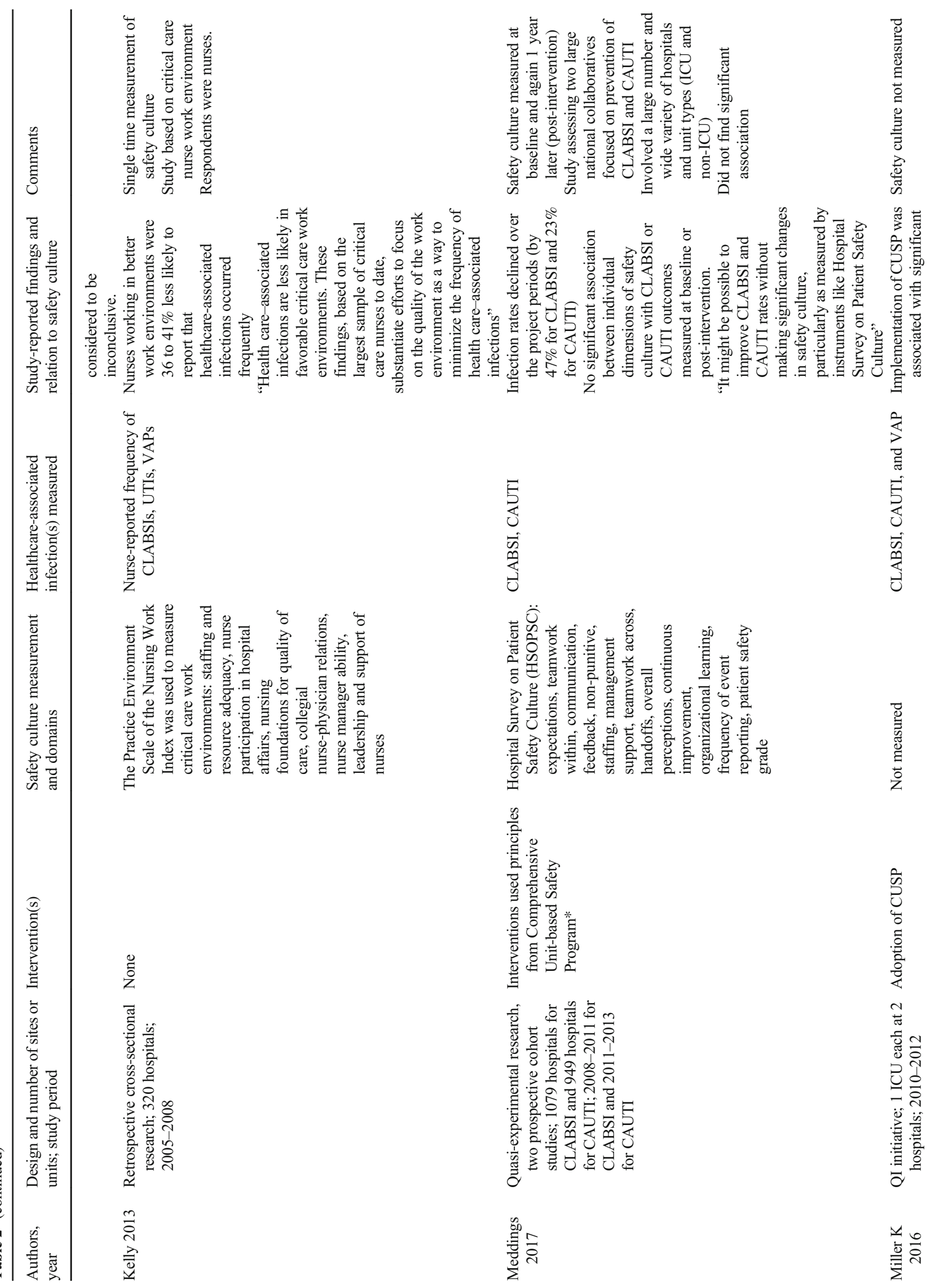




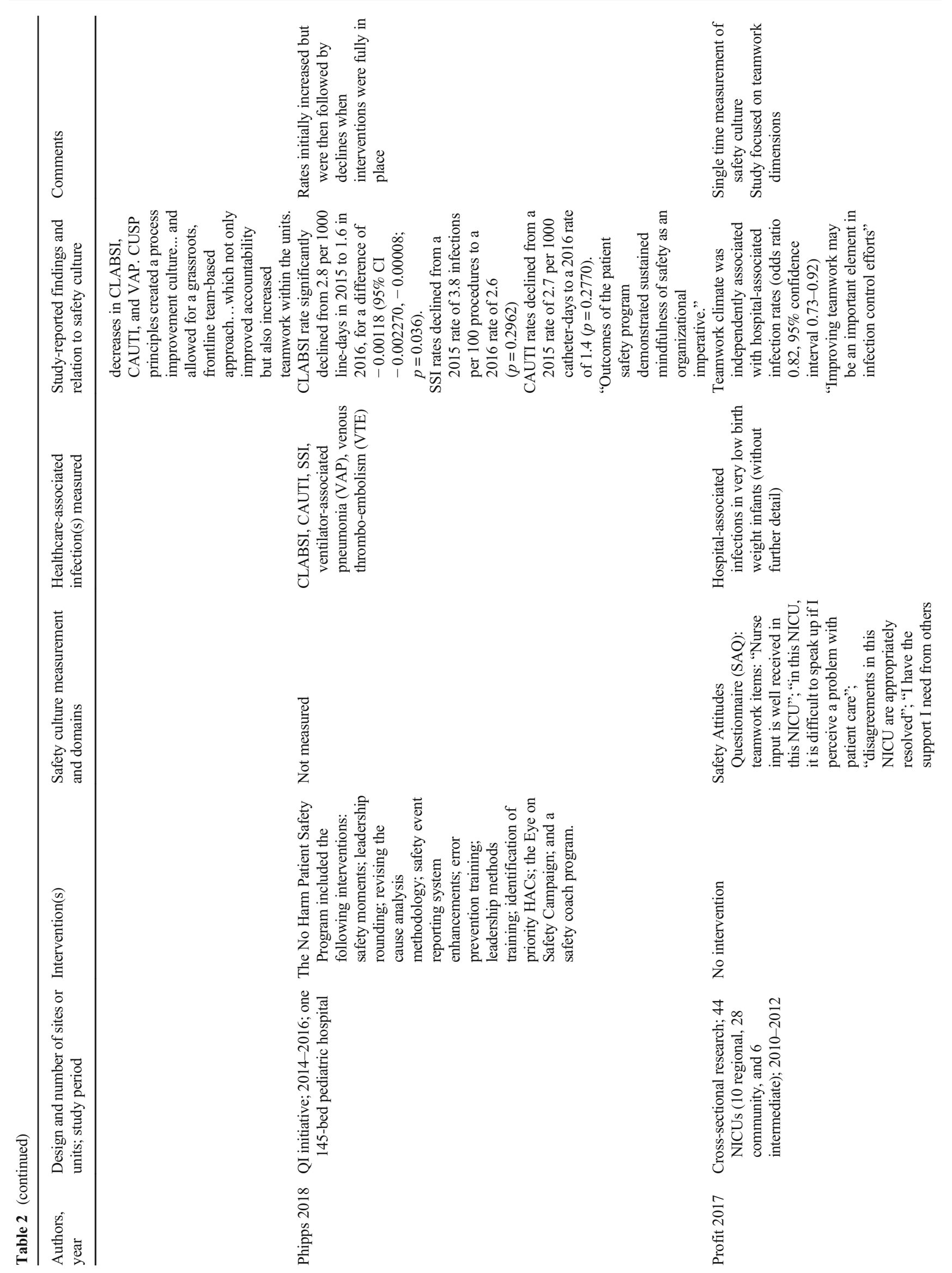




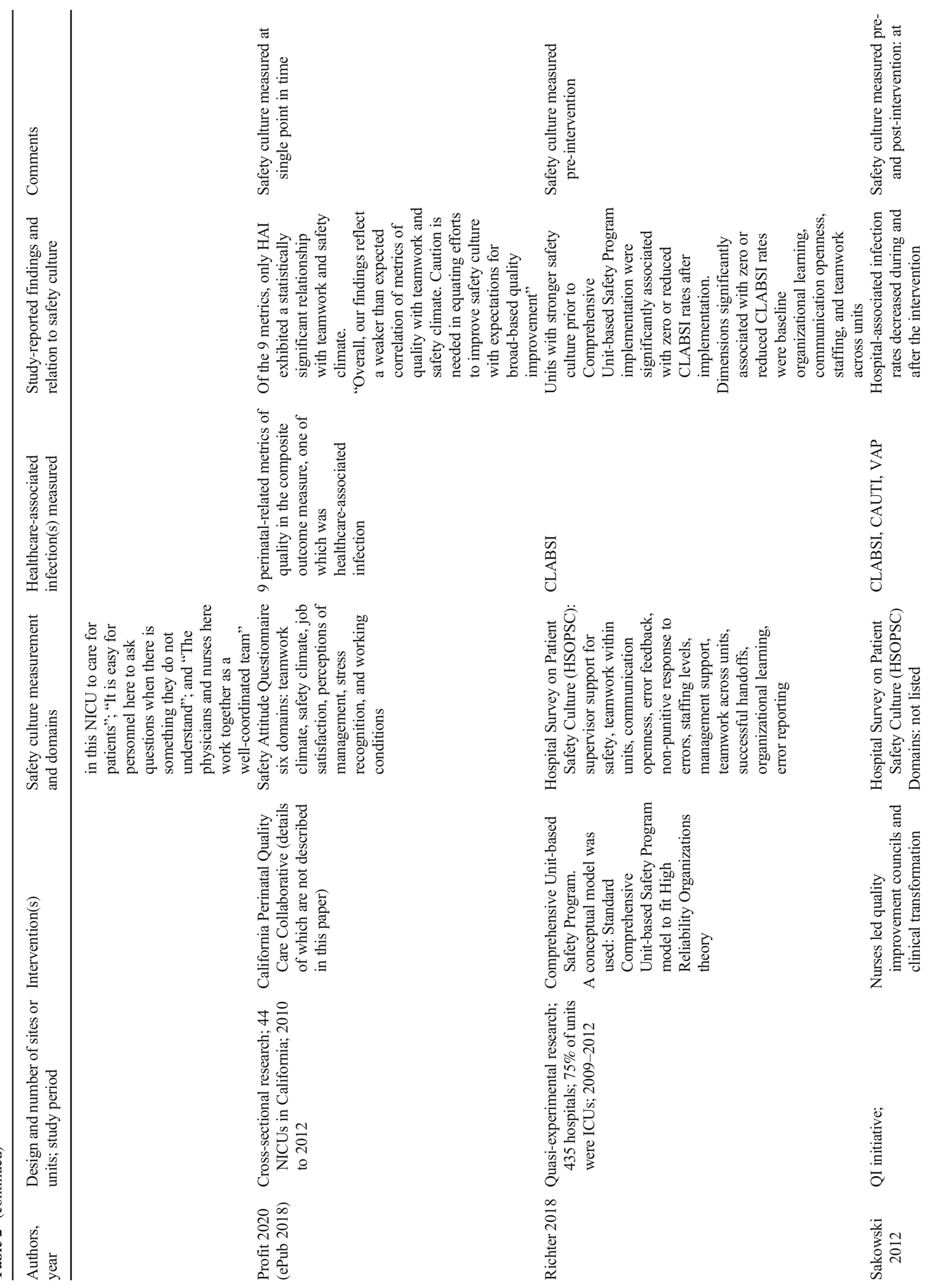




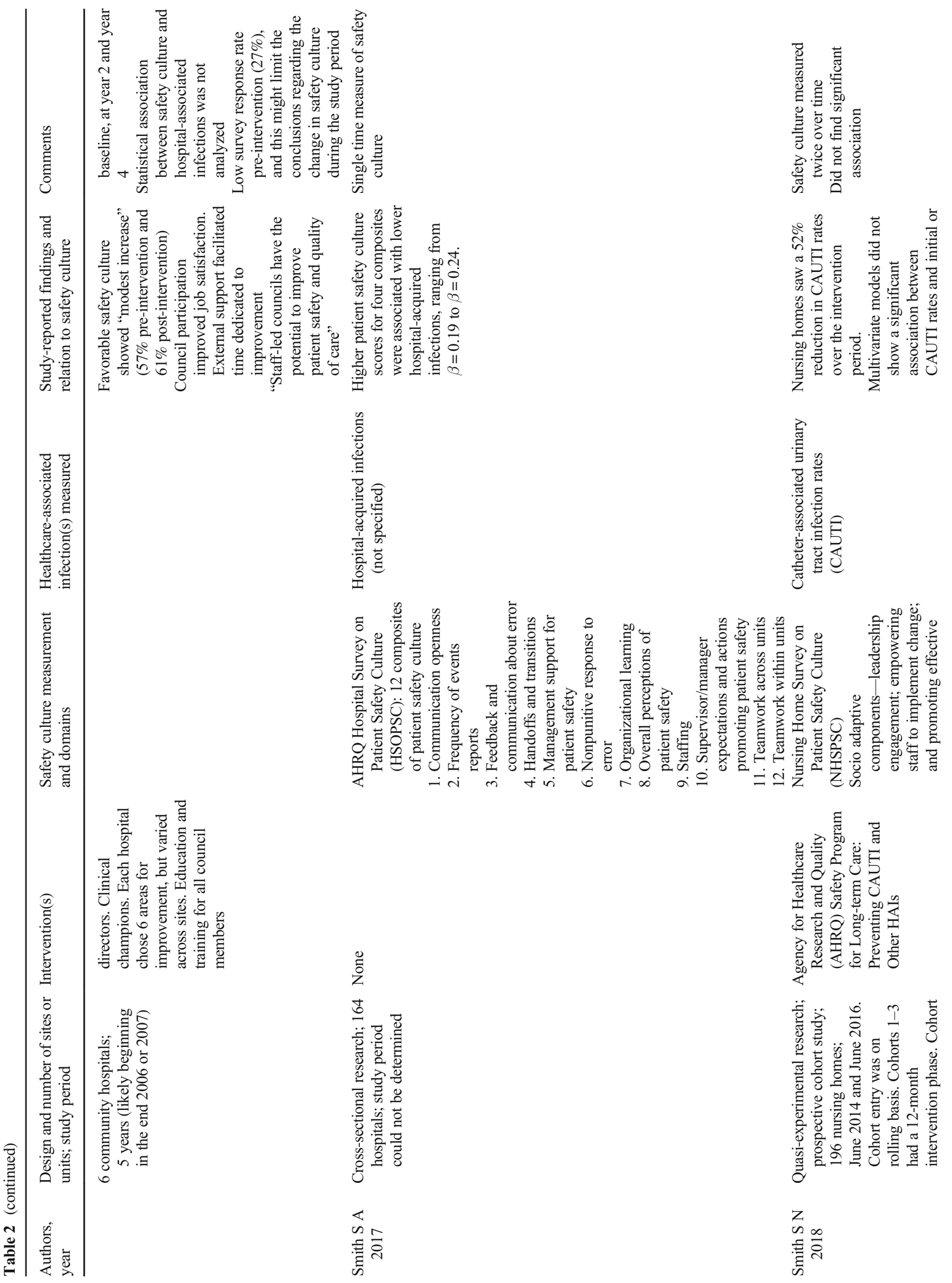




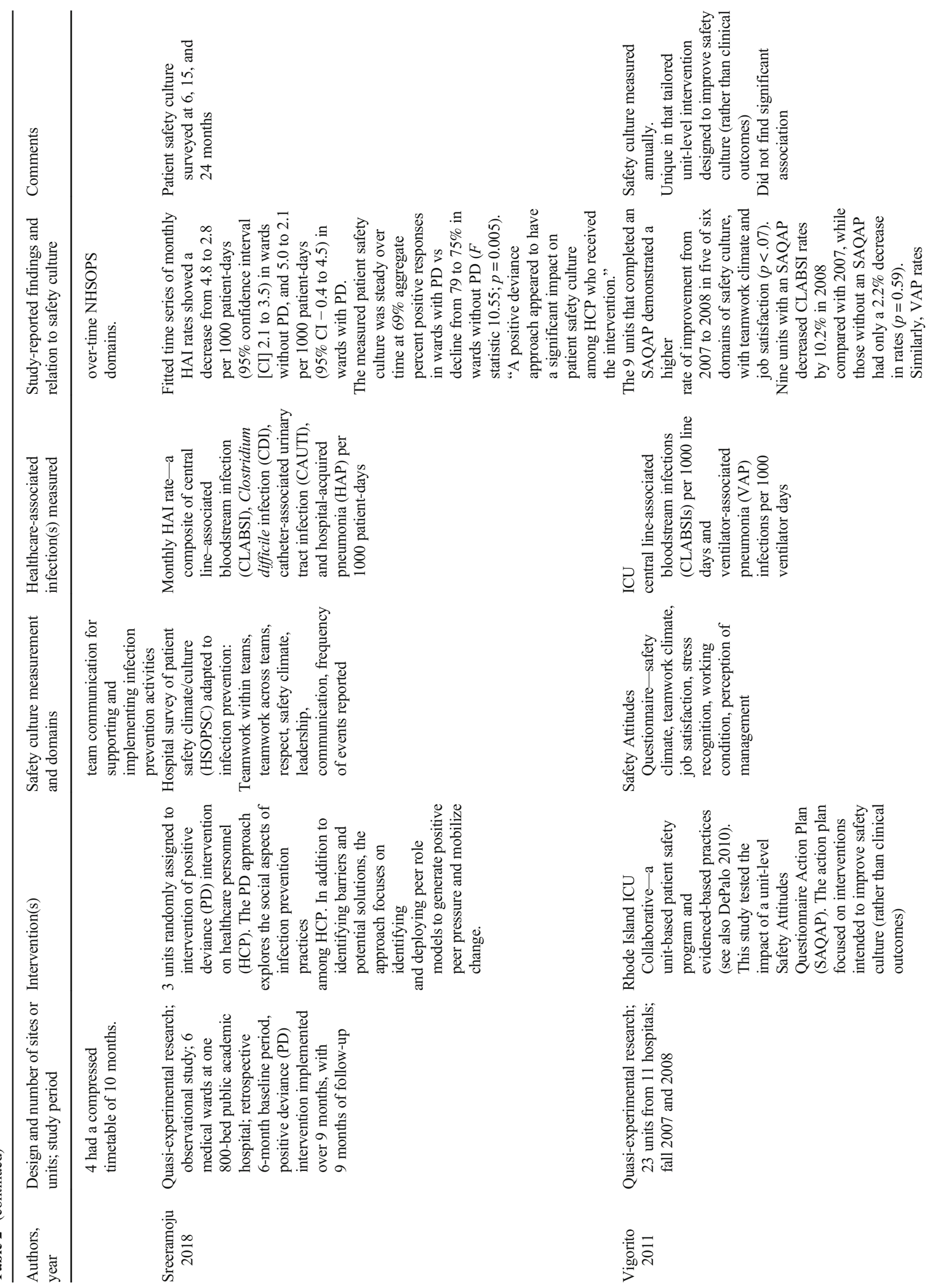




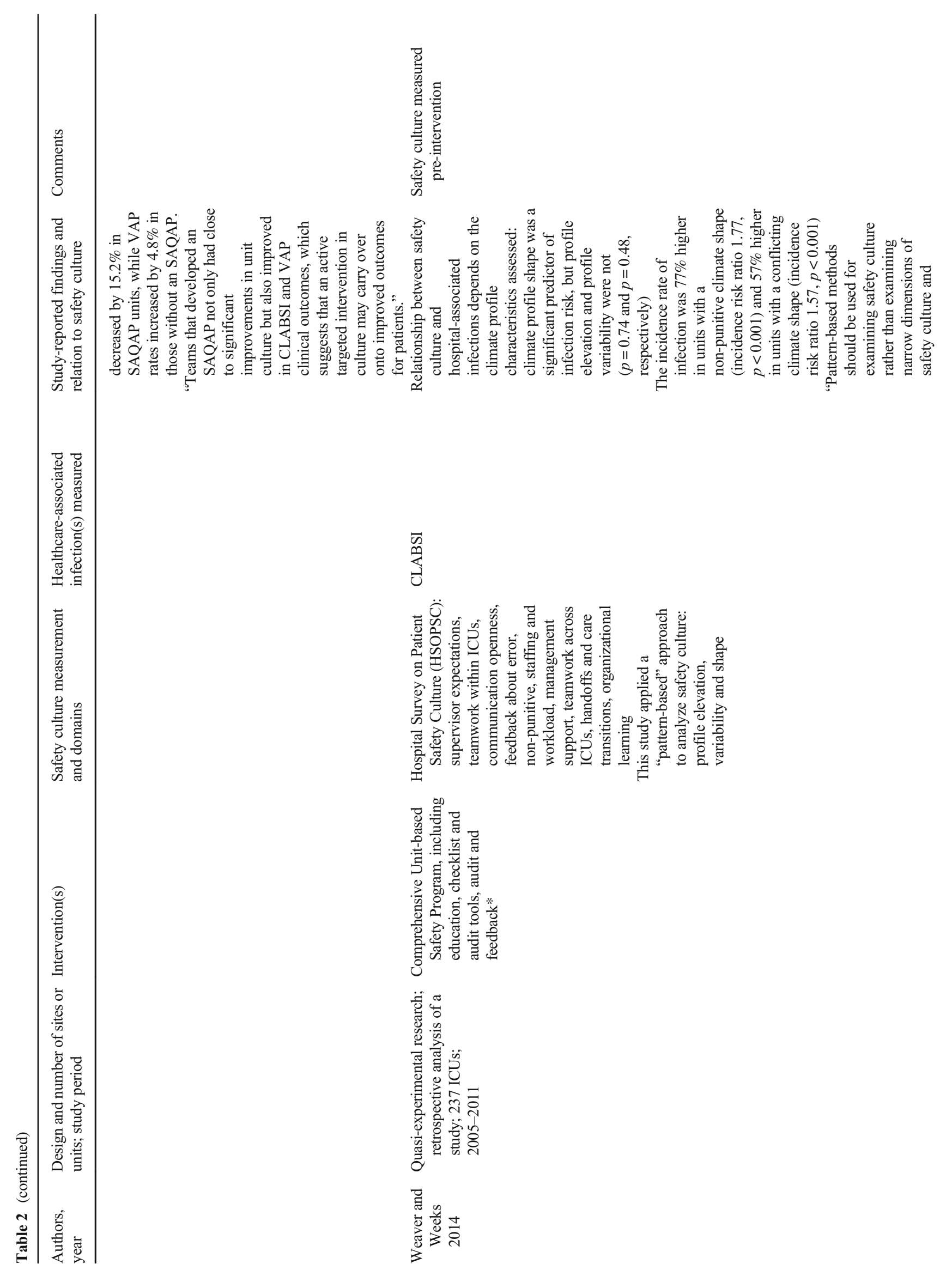




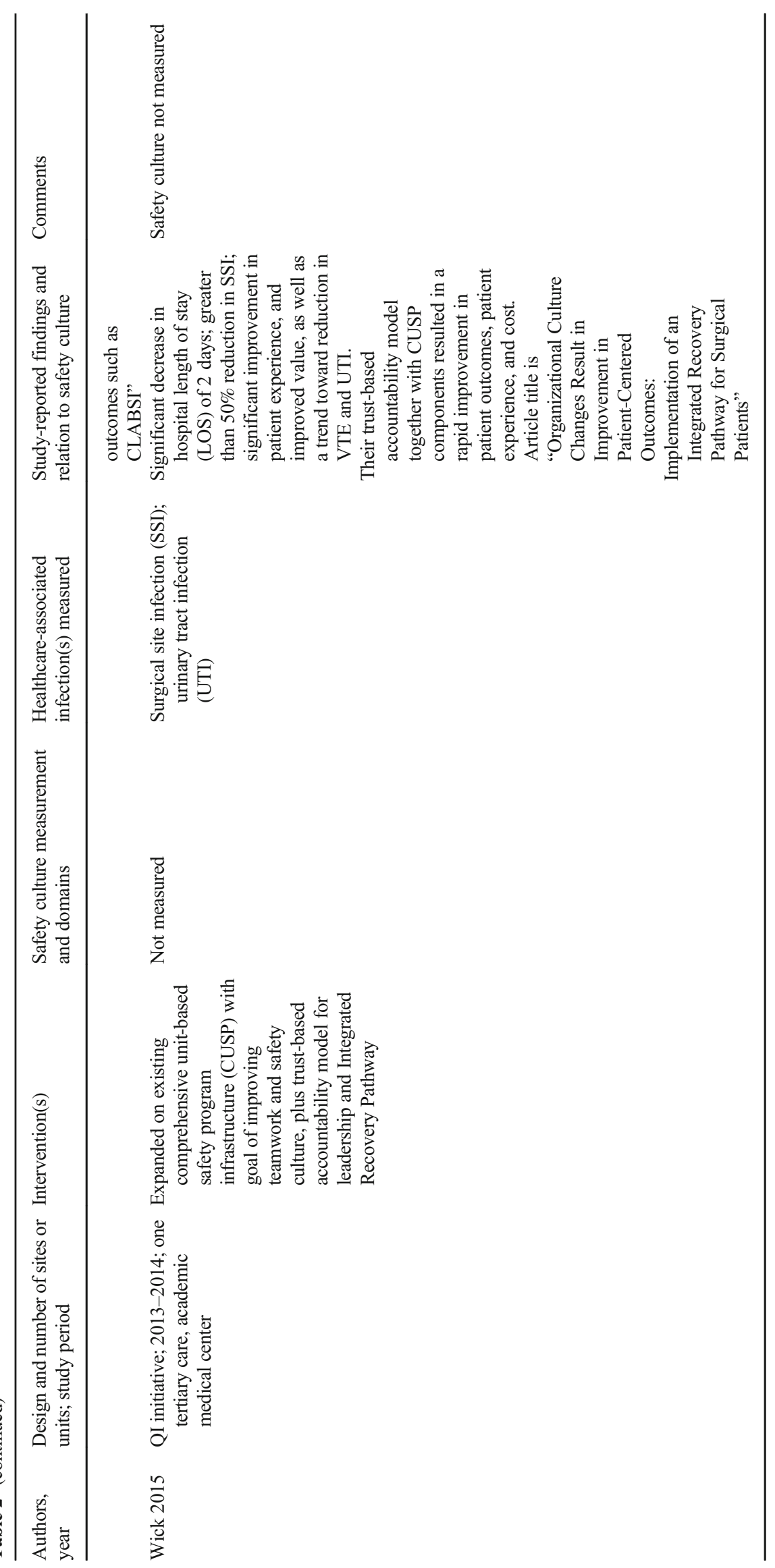



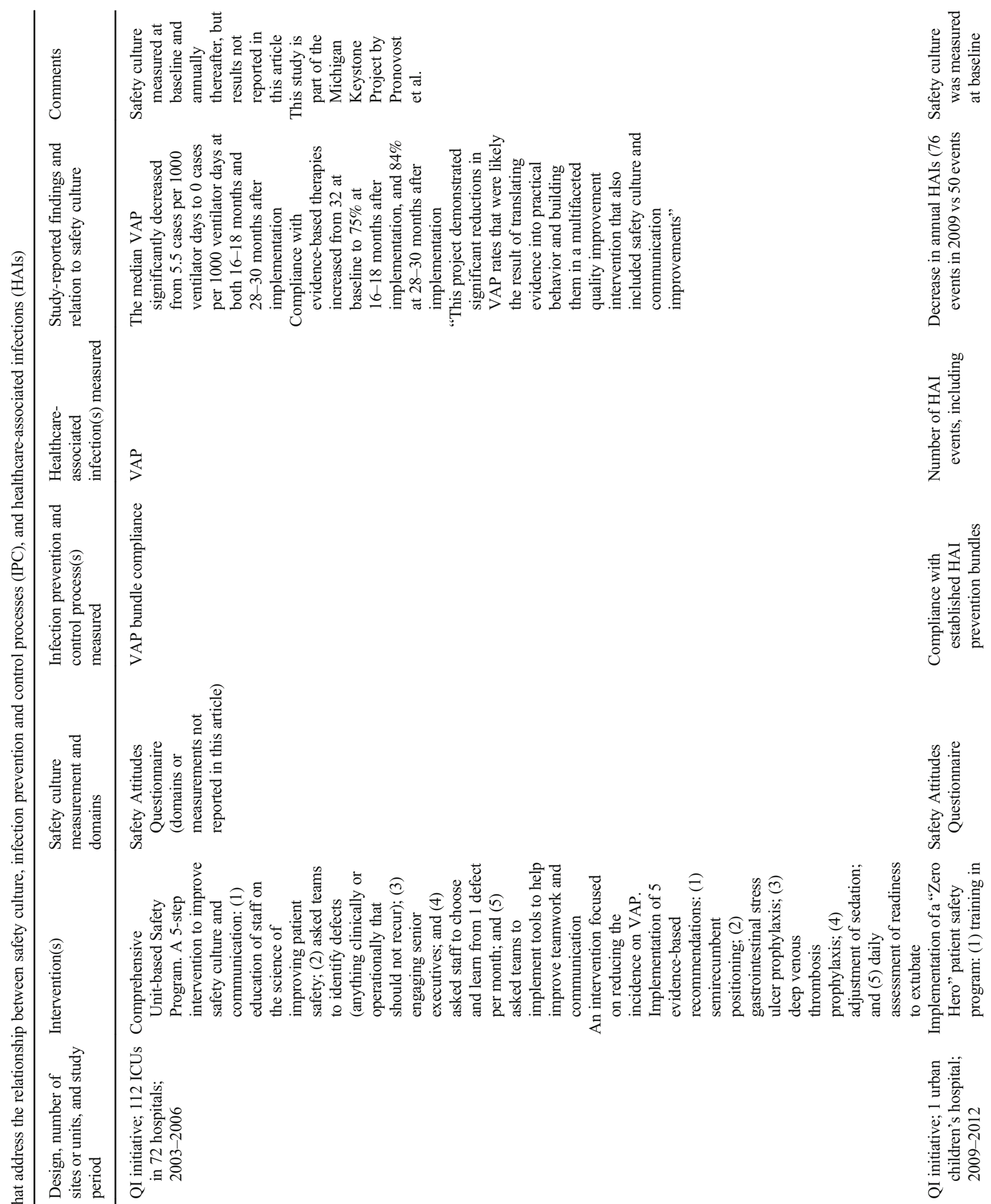

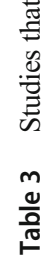

$$
\text { }
$$




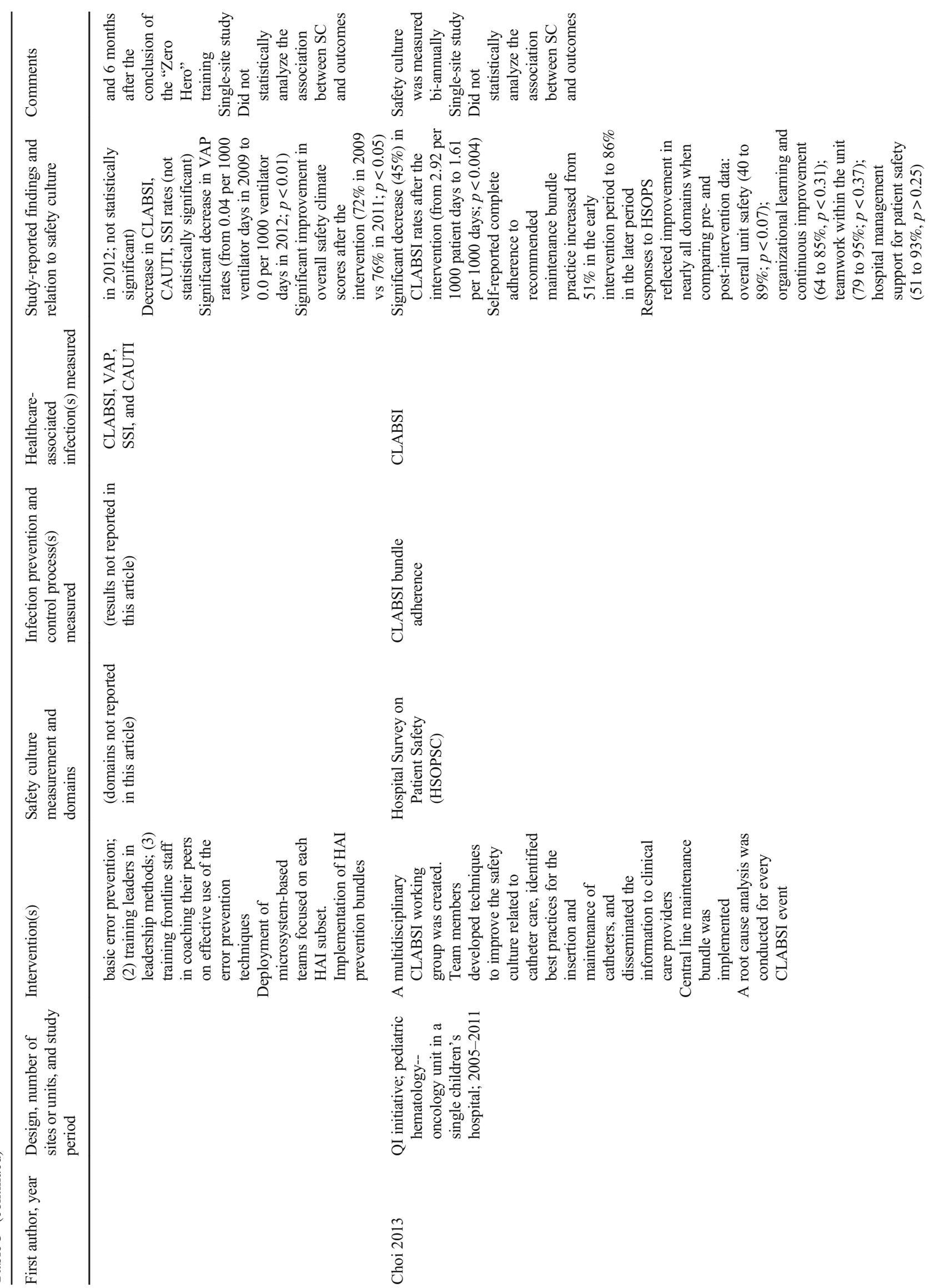




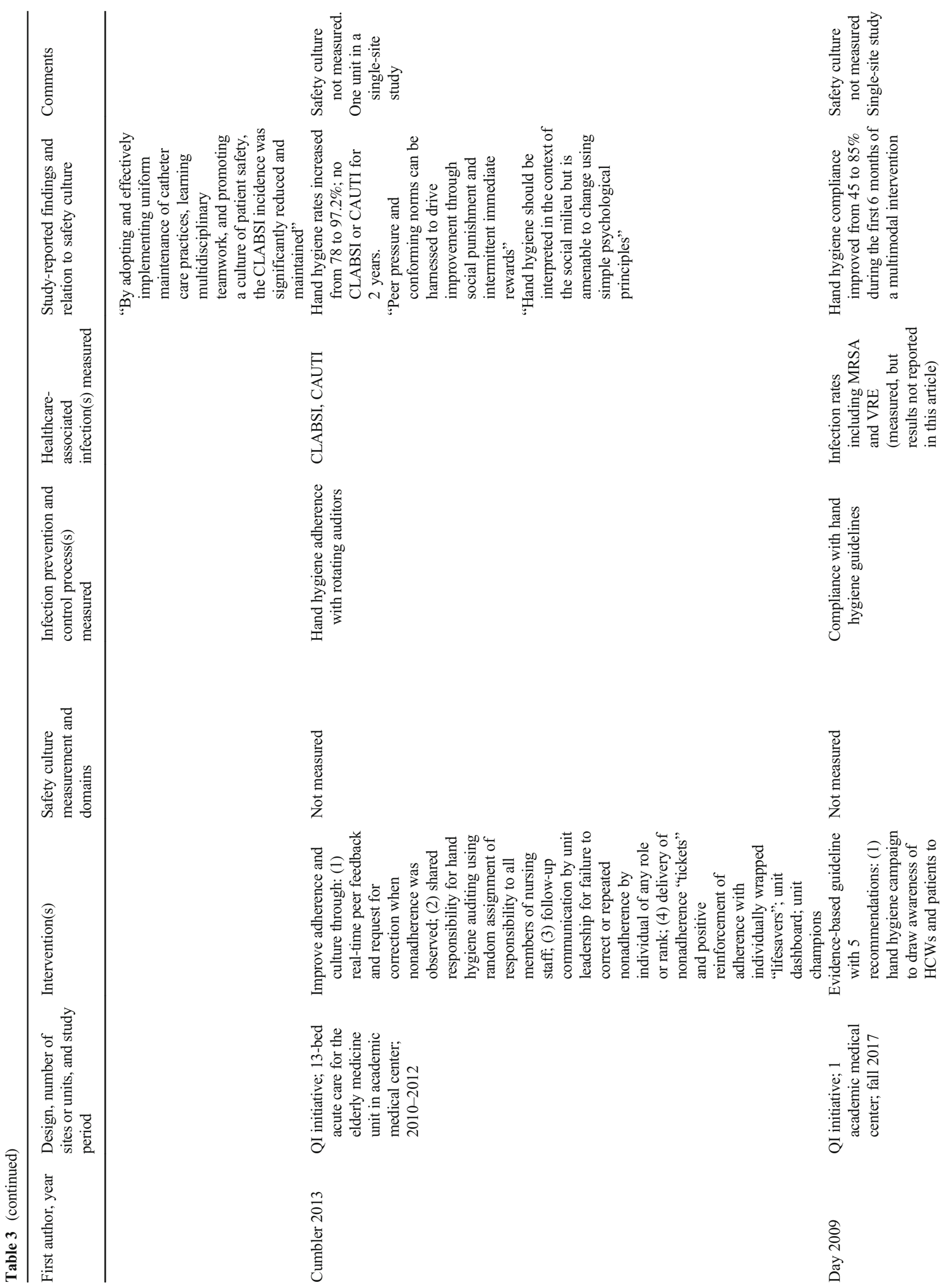




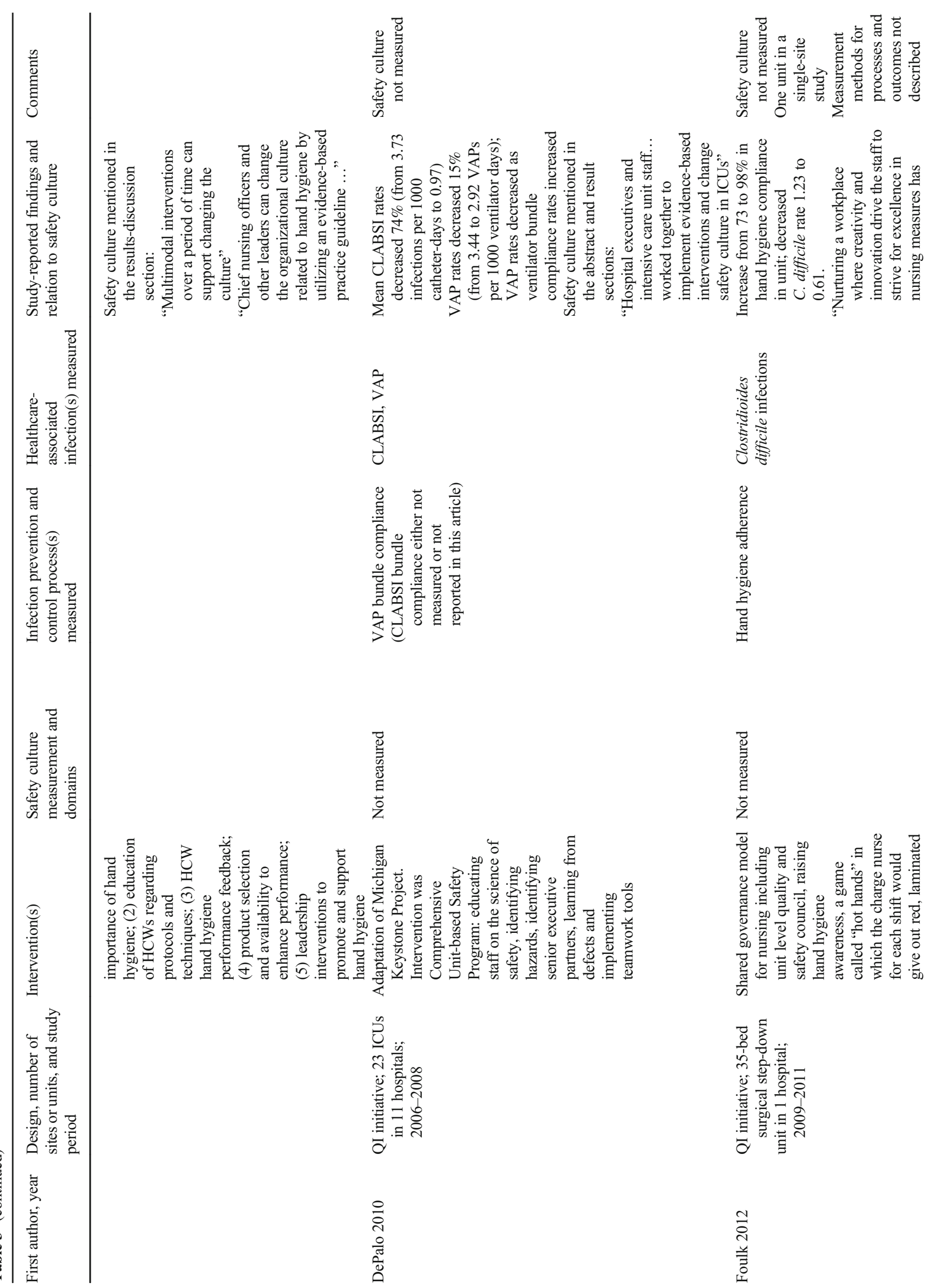




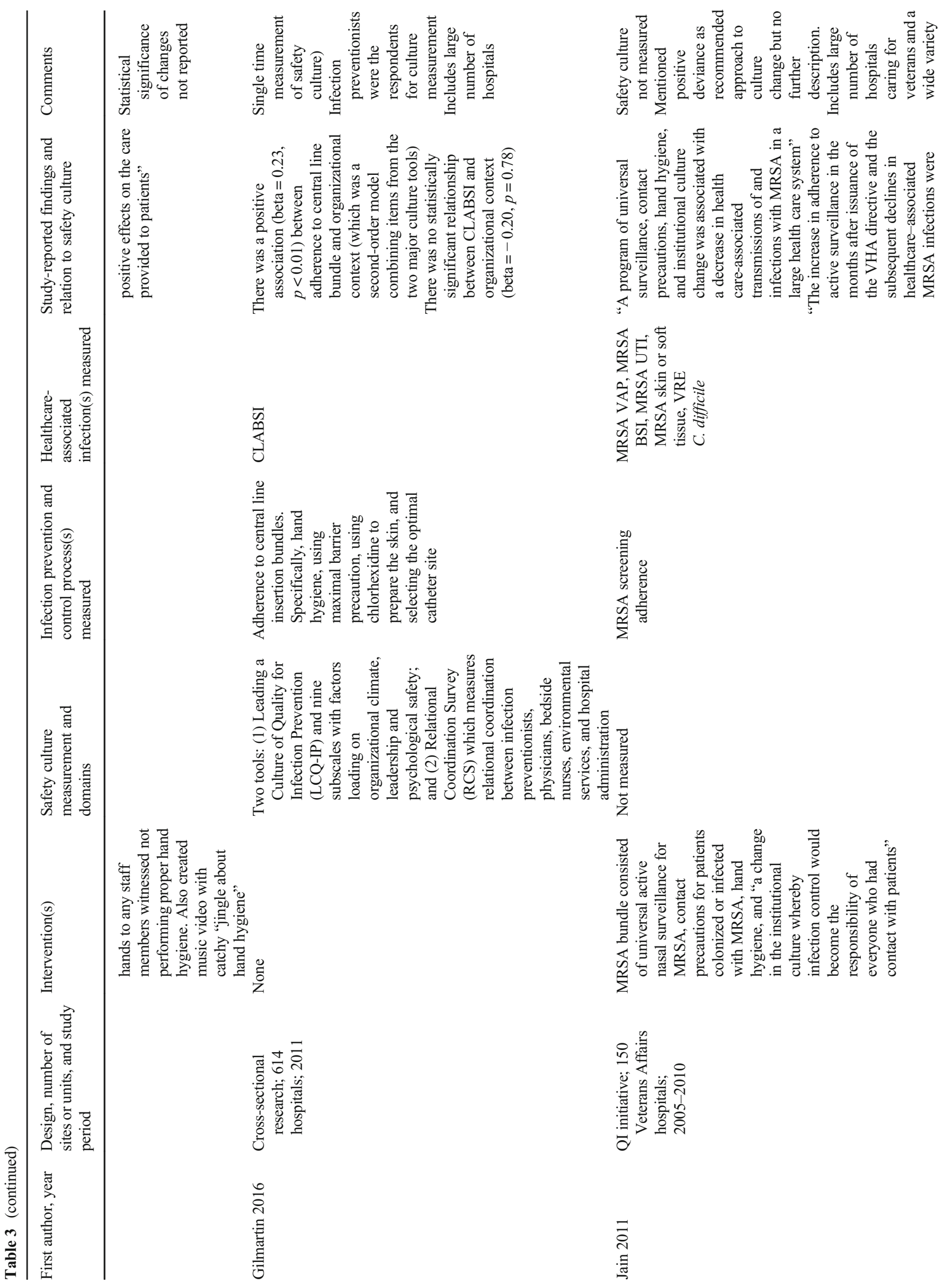




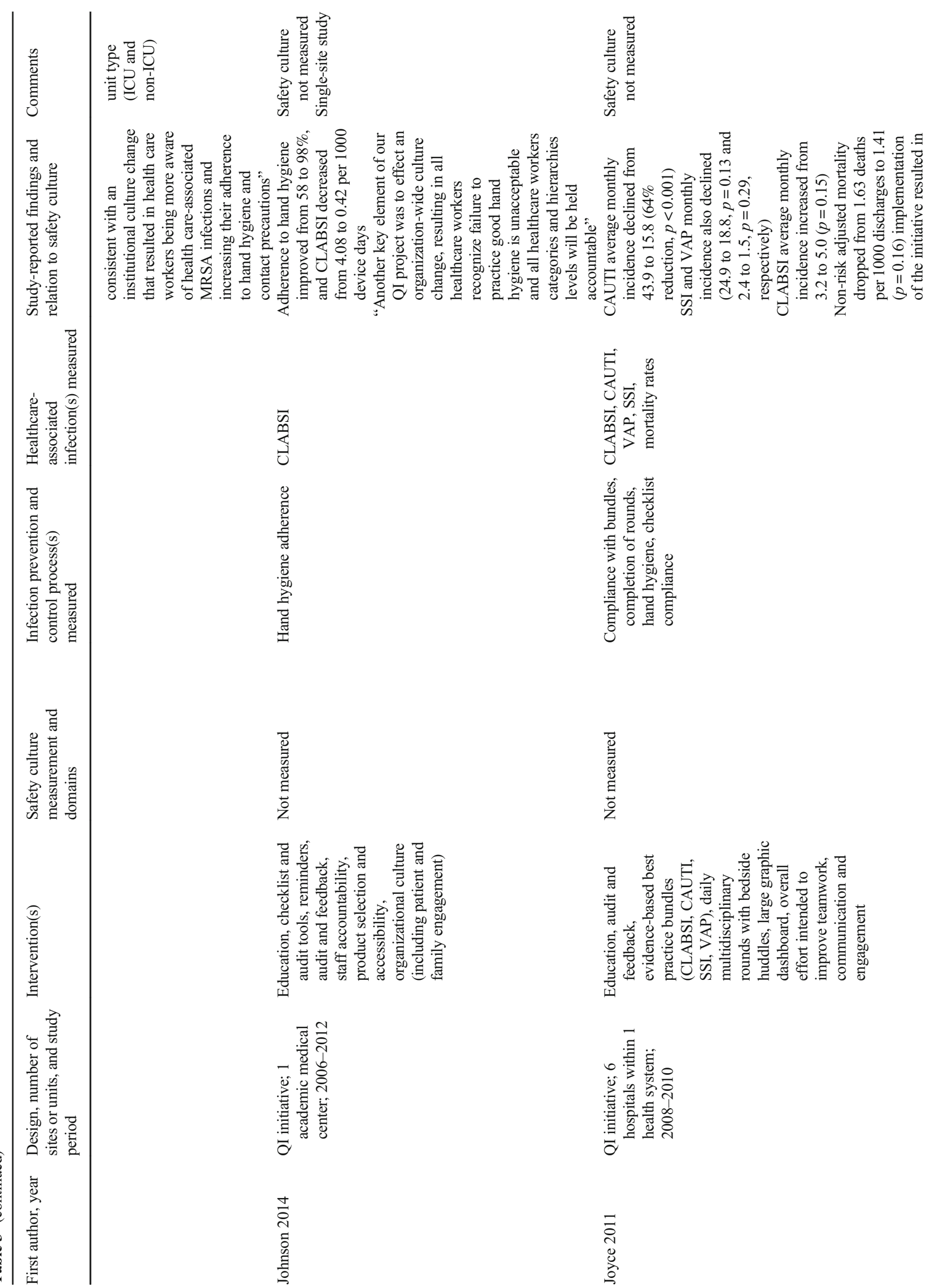




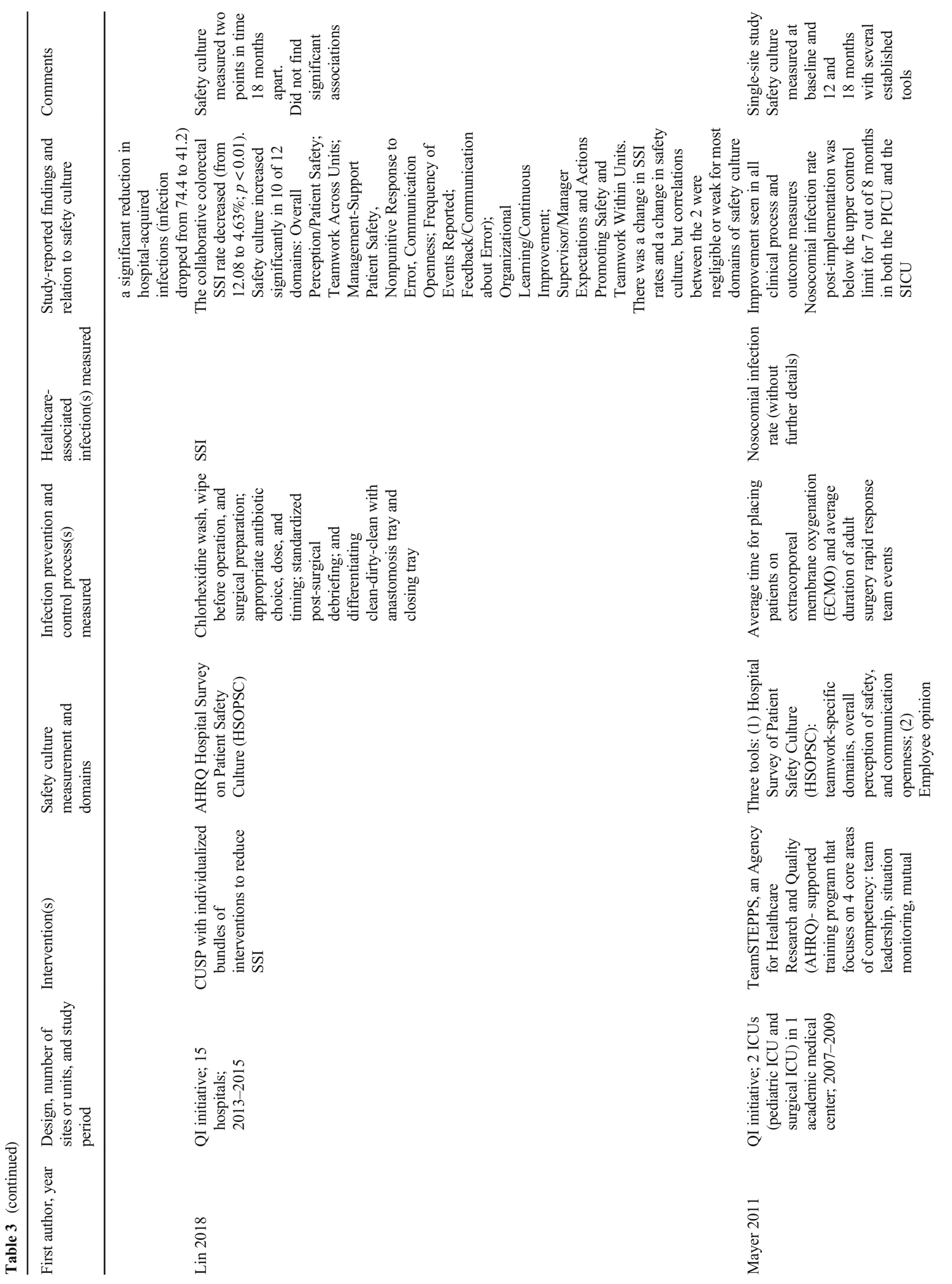




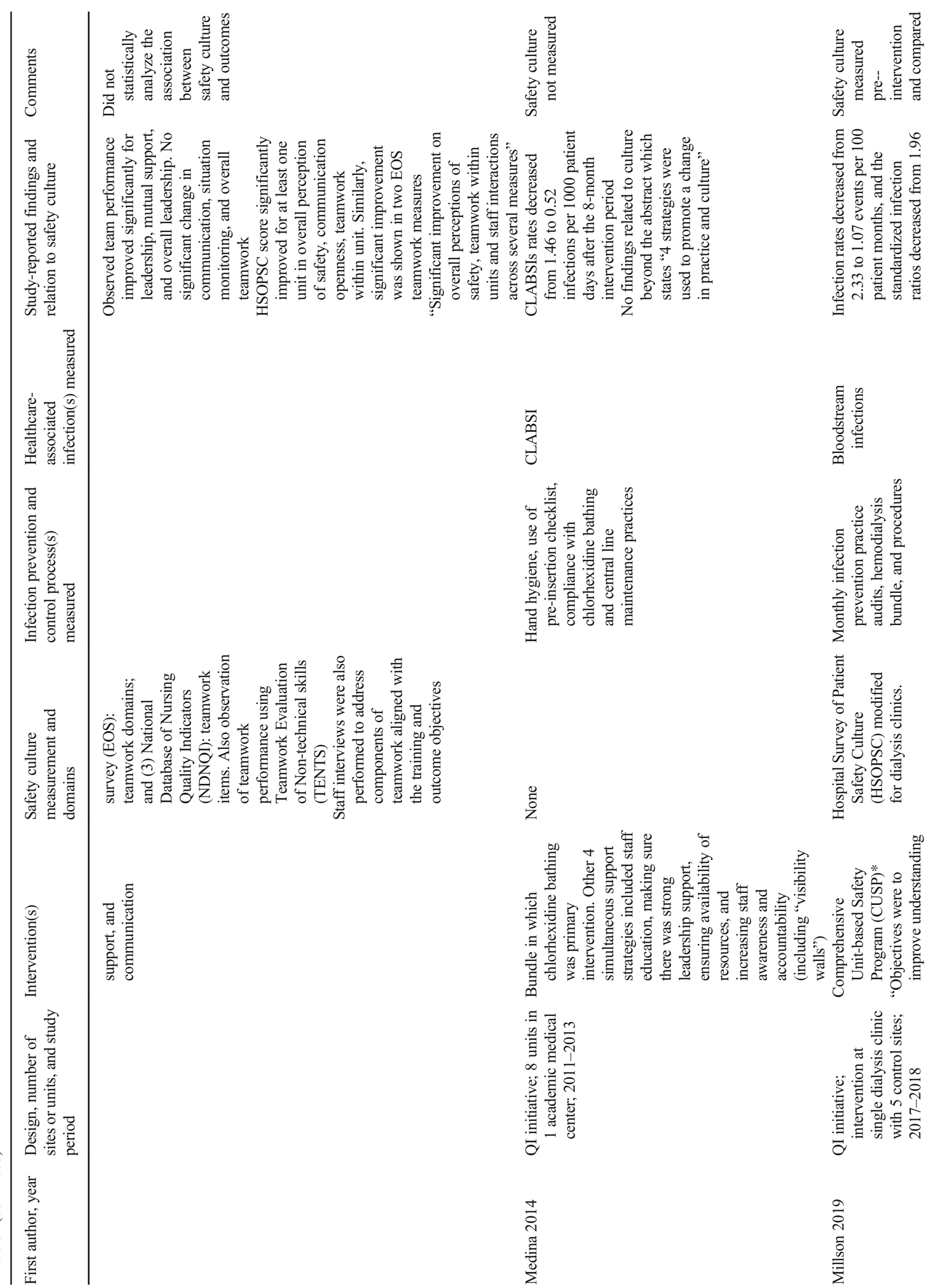




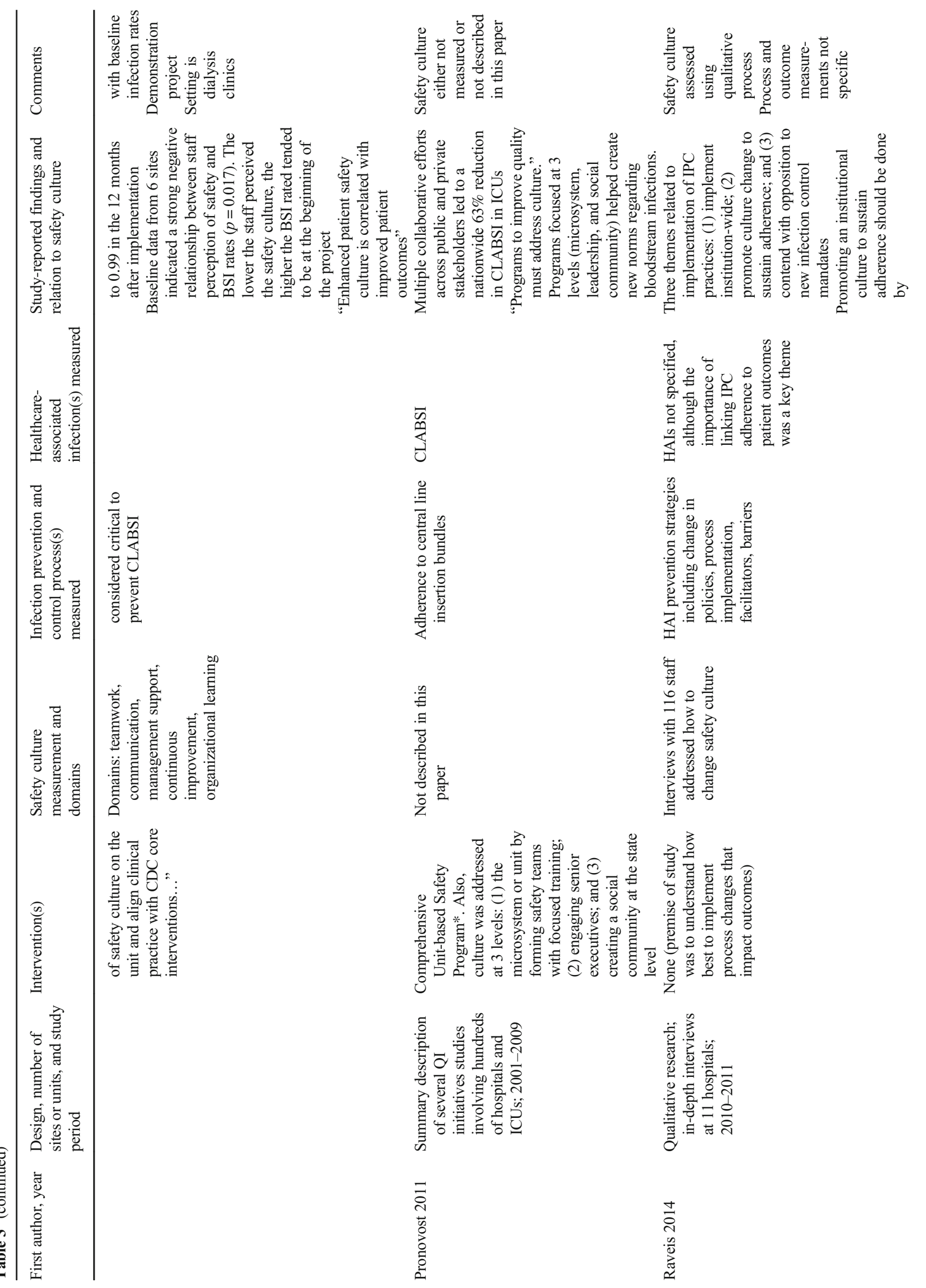




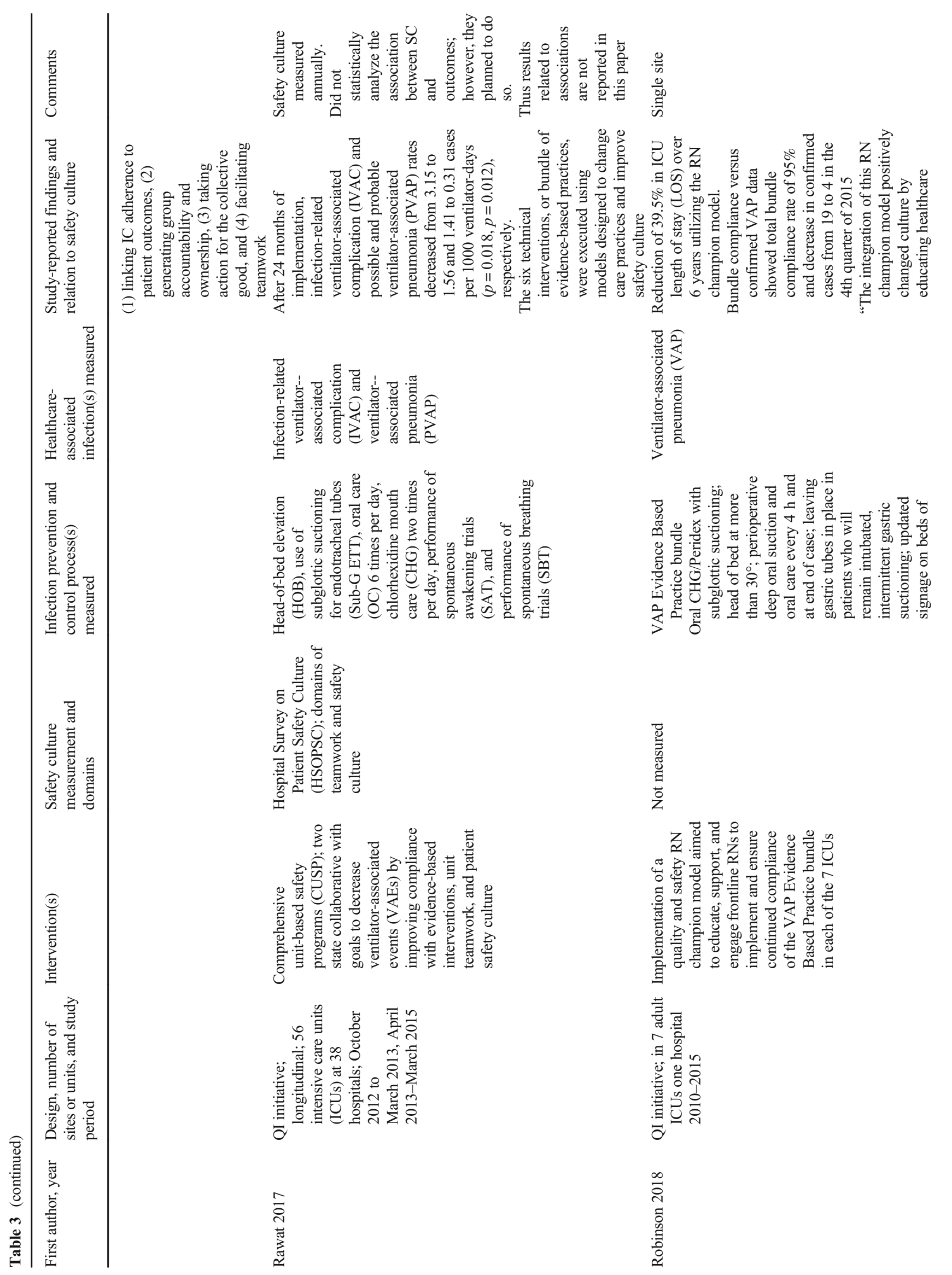




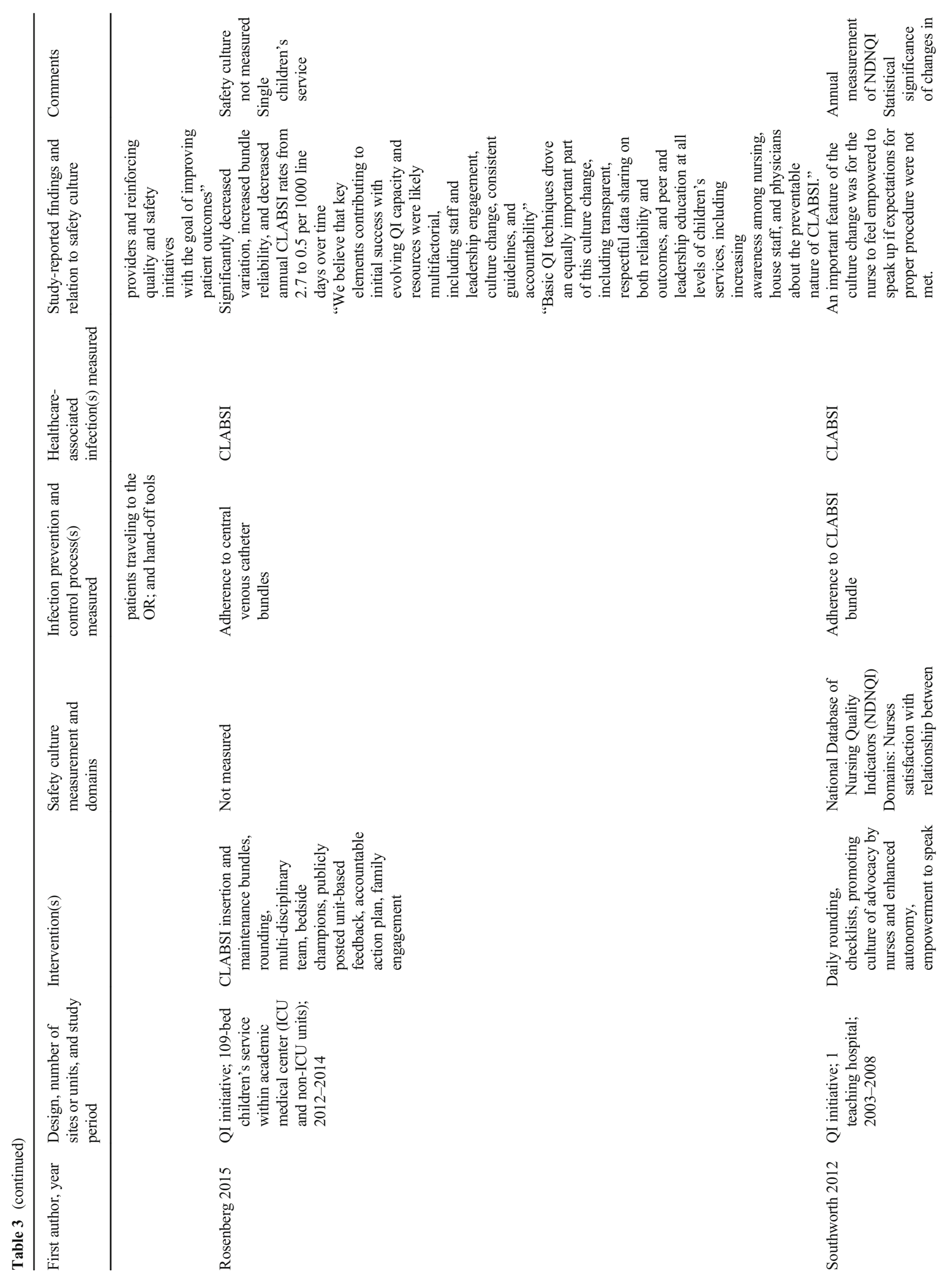




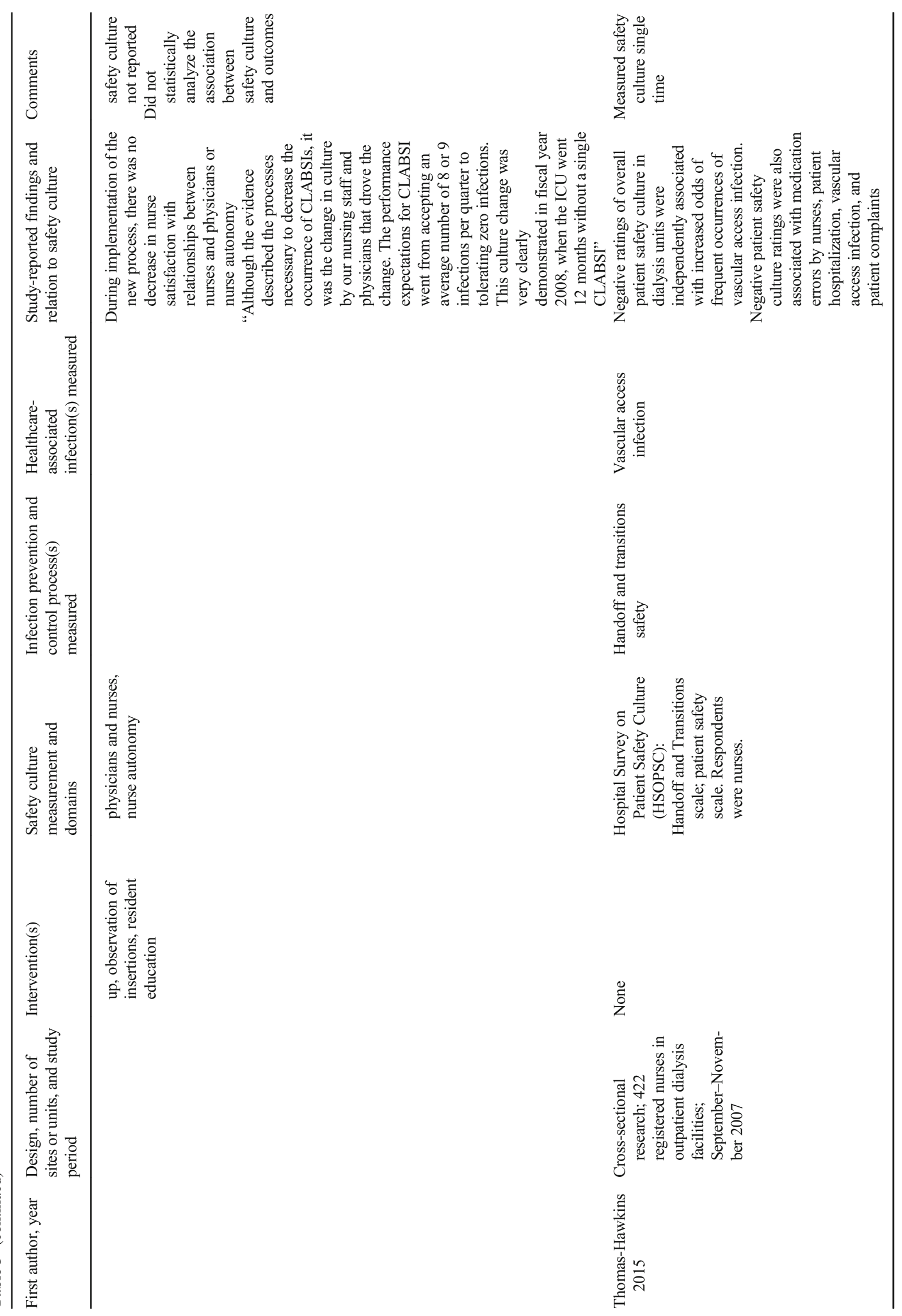


112], and two articles focused on organism-specific HAIs (e.g., MRSA and VRE) $[63,111]$. Two articles did not specify the type of HAI measured [74, 114].

\section{Relationship Between Safety Culture and Improvements in IPC Process and Patient Outcomes}

Across all 55 articles (regardless of whether they measured or analyzed safety culture), 51 (92.7\%) concluded there was an association between safety culture and IPC process and/or HAIs. A summary of the conclusions about the relationship between safety culture, IPC, and HAI is presented in Table 4.

Of the 39 that measured safety culture, only $26(67 \%)$ tried via statistical analysis to establish an association between safety culture and IPC process or HAIs. Statistical analyses varied by design.

Among the 28 QI projects, only 12 measured safety culture and 3 tried to establish a statistical association between safety culture and IPC process or HAIs. Nevertheless, almost all QI projects $(27$ out of $28,96 \%)$ concluded there was a relationship between safety culture and outcomes. One of the 3 QI projects that measured safety culture and tried to establish a statistical association between safety culture and outcomes did not find a statistically significant relationship between culture and IPC process or HAIs [73].
By comparison, all 27 research articles measured safety culture. Of these, $23(85.2 \%)$ tried to establish a statistical association between safety culture and IPC process or HAIs. Nineteen of the $23(82.6 \%)$ identified a statistically significant association with IPC process, HAIs, or both. Among those that did not find an association were 2 of the largest quasi-experimental studies $[68,80]$ and 1 cross-sectional study [83]. Another smaller quasi-experimental study with an intervention exclusively focused on improving safety culture also did not find significant association [86].

\section{Discussion}

The goal of this review was to examine recent literature on the relationship between safety culture and IPC processes and outcomes in U.S. healthcare organizations. In so doing, we also sought to characterize the challenges to empirically establishing these relationships as well as limitations of current research.

The 55 articles reviewed varied considerably regarding purpose, design, safety culture measurement tools and respondent, and outcome (IPC process and/or HAI) measurement, although several were based on the CUSP model. This

Table 4 Summary of articles that related safety culture to infection prevention and control (IPC) processes or healthcare-associated infections (HAIs)

\begin{tabular}{|c|c|c|c|c|c|}
\hline $\begin{array}{l}\text { Study design and } \\
\text { sites }\end{array}$ & $\begin{array}{l}\text { Total } \\
\text { number } \\
\text { of } \\
\text { studies }\end{array}$ & $\begin{array}{l}\text { Number } \\
\text { measured } \\
\text { safety } \\
\text { culture }\end{array}$ & $\begin{array}{l}\text { Number attempted to } \\
\text { statistically associate safety } \\
\text { culture and IPC process or } \\
\text { HAI }\end{array}$ & $\begin{array}{l}\text { Number identifying a statistically } \\
\text { significant association between } \\
\text { safety culture and IPC process or } \\
\text { HAIs }\end{array}$ & $\begin{array}{l}\text { Number concluding safety culture } \\
\text { influenced IPC process or HAI or } \\
\text { that safety culture improved }\end{array}$ \\
\hline $\begin{array}{l}\text { Qualitative; single } \\
\text { site }\end{array}$ & 1 & 1 & $\mathrm{n} / \mathrm{a}$ & $\mathrm{n} / \mathrm{a}$ & 1 \\
\hline $\begin{array}{l}\text { Qualitative; } \\
\text { multiple sites }\end{array}$ & 3 & 3 & No & $\mathrm{n} / \mathrm{a}$ & 3 \\
\hline $\begin{array}{l}\text { Cross-sectional; } \\
\text { single site }\end{array}$ & 1 & 1 & 1 & 1 & 1 \\
\hline $\begin{array}{r}\text { Cross-sectional; } \\
\text { multiple sites }\end{array}$ & 16 & $\begin{array}{l}16 \text { single } \\
\text { time }\end{array}$ & 16 & 15 & 14 \\
\hline $\begin{array}{l}\text { Quality } \\
\text { improvement } \\
\text { initiative; single } \\
\text { site }\end{array}$ & 16 & $\begin{array}{c}5 \text { multiple } \\
\text { times }\end{array}$ & - & - & 16 \\
\hline $\begin{array}{l}\text { Quality } \\
\text { improvement } \\
\text { initiative; } \\
\text { multiple sites }\end{array}$ & 12 & $\begin{array}{l}1 \text { single } \\
\text { time } \\
6 \text { multiple } \\
\text { times }\end{array}$ & 3 & 2 & 11 \\
\hline $\begin{array}{l}\text { Quasi-experimental } \\
\text { research; single } \\
\text { site }\end{array}$ & 1 & 1 & 1 & 1 & 1 \\
\hline $\begin{array}{l}\text { Quasi-experimental } \\
\text { research; multiple } \\
\text { sites }\end{array}$ & 5 & $\begin{array}{l}2 \text { single } \\
\text { time } \\
3 \text { multiple } \\
\text { times }\end{array}$ & 5 & 2 & 3 \\
\hline Total & 55 & 39 & 26 & 21 & 51 \\
\hline
\end{tabular}


heterogeneity contributes to the previously described challenges to linking safety culture, IPC processes and outcomes.

Nevertheless, most of the QI and research articles that measured safety culture and statistically analyzed the associations concluded that safety culture was positively associated with IPC processes and negatively associated with HAIs. Thus, our findings are generally consistent with other reviews supporting the notion that an association exists $[42 \bullet, 43 \bullet \bullet, 44 \bullet \bullet]$.

Interestingly, a greater proportion of QI articles than research articles concluded there was a relationship with safety culture. All but one of the QI projects concluded that safety culture improved over time, even though less than $1 / 2$ of the QI projects actually measured safety culture.

Why is it that so many QI studies concluded there was a relationship even in the absence of measuring safety culture? Do the QI studies share a common assumption that safety culture must have improved? In the absence of empirical data, should we dismiss all the QI studies that did not measure culture and limit conclusions to the traditional research studies? Were this a systematic review that only included studies with rigorous designs, we would have to conclude there is limited evidence to support the relationship between safety culture and IPC and HAIs because of weak designs.

We propose an alternative explanation. Perhaps one should instead accept the experience reported by authors that culture did change, even if not measured in a quantifiable way. As described in the tables, authors often expressed that they saw or felt a culture change which was integral to the effectiveness of the improvement effort. In fact, it is quite possible that culture did improve in certain domains because of the increased attention of leadership, extra resources, incentives, and momentum to drive change. Awareness and attitudes about the preventability of HAIs likely changed through education, and a sense of teamwork likely improved through the shared experience of working toward a common, measurable goal. This notion is highly consistent with the multi-faceted CUSP approach to improvement initiatives.

On the other hand, it is important to note that some research studies with the strongest methodologies (large numbers of sites, multiple outcomes, and longitudinal design) did not find an association between safety culture, IPC process, and HAIs (e.g., $[68,80])$. Meddings et al. suggest that improvements in HAIs occurred by means other than improving safety culture, such as a strong emphasis on standardizing technical components of care, and that changing safety culture may not be critical to improvement [68]. Alternatively, they also suggest that safety culture may have improved and been instrumental in improving outcomes but could have been inadequately measured. In response, others have argued that the conclusions drawn by Meddings were unrelated to the instrument and inadequately supported by the methods and analyses [115].
So, what are the practical implications of the findings? Should one continue measuring safety culture and trying to establish relationships with outcomes? What does this say about targeting interventions to improve safety culture? Some insight into this question comes from the review by De Bono [44••]. They state that strategies aimed at achieving long-term improvement in IPC performance need to be multimodal in order to both reflect and address the multidimensionality of the structure and the dynamic of organizational culture. They state "the link between compliant behavior and culture may seem to be plausible and sometimes obvious. But when empirically measured, the relationship might be weaker than expected, probably due to a long chain of mitigating factors and confounders."

De Bono and colleagues also argue that strategy and organizational culture are inextricably intertwined in that all attempts at organizational culture change should be viewed as strategic changes $[44 \cdot 0]$. The notion that strategy and culture are inextricably intertwined helps explain why so many healthcare organizations in this review experienced a culture change while implementing strategies for improvement. Regarding causal direction, it may well be that implementing effective QI intervention strategies influences culture as much or more than interventions to change culture affect IPC processes and HAIs.

Regardless of the inter-relationships between safety culture, process, and outcome, there remains value in assessing safety culture. This value includes the ability to better understand staff perceptions and attitudes, identify opportunities for improvement, find differences across units and healthcare worker roles, comply with recommendations and requirements of oversight groups, and effectively implement interventions that ultimately benefit staff and patients.

\section{Research Gaps}

We identified several gaps in need of future research. Foremost is the need for longitudinal, cluster randomized trials with the explicit purpose of assessing the impact of safety culture, while controlling for the effect of specific interventions. Greater rigor in design would overcome many of the weaknesses inherent in uncontrolled observational studies. More research is also needed in non-hospital settings. It would be interesting to know if the relationships would be similar, stronger, or weaker in settings that are less organizationally complex than hospital, such as nursing homes and specialty clinics.

Similarly, more studies that directly measure safety culture over time are needed to better understand the sensitivity to change of safety culture instruments. Greater attention to fine tuning analysis for specific subgroups is also needed. For example, do associations between safety culture and IPC process vary depending on the role of the person completing the safety 
culture assessment (frontline staff vs leadership), the domains within safety culture (e.g., teamwork, communication, leadership), or the HAI of interest? Also, to what extent do studies at the unit-level generalize to organizational level findings?

\section{Limitations}

Our review has several important limitations. It was not intended to be a systematic review, and we did not formally evaluate the quality of studies. Nor should it be considered a comprehensive scoping review because we did not strive to assess the breadth of literature on this topic. We did not include gray literature that was not peer reviewed.

We only searched one citation database (PubMed). Other databases such as CINAHL, PsycINFO, EMBASE, and Cochrane might have yielded more studies. We excluded studies done outside the U.S.A. in part because of differences in facility characteristics and payment systems across borders which could confound the relationships of interest. There is a substantial body of work on this topic in European, Asian, and other regions which might have led to different conclusions (e.g., $[116,117])$. The choice of search terms and PubMed field types may have been too limited. We also may have missed studies due to publication bias in that studies lacking associations between safety culture and IPC process or HAIs may never have been submitted or published.

Finally, in our analysis, we did not consider other related factors such as leadership styles and issues specific to the measurement tools. Admittedly, lumping together tools that measure culture and climate further conflates the distinction in instruments and does nothing to address psychometric concerns related to validity, reliability, and domain-specific issues.

\section{Conclusions}

Safety culture appears to be related to IPC processes and HAI outcomes. The associations with the IPC process may be bi-directional in that positive safety culture contributes to the success of interventions and implementing interventions drives improvements in safety culture. In the absence of longitudinal controlled trials, it may not be possible to separate the effect of safety culture from that of implementing effective intervention strategies on HAIs. Nevertheless, there remains value in evaluating safety culture in order to understand staff perceptions, identify opportunities for improvement, and implement interventions that ultimately benefit staff and patients.

Acknowledgments The authors are sincerely grateful to medical librarians Janet Aleccia MALS and Laura Shedore MLIS, to Tasha Mearday BS for administrative assistance, and to Brette Tschurtz MPH, Scott
Williams PsyD, and Kenneth Soyemi MD MPH MBA for thoughtful review.

Authors' Contributions The project was conceptualized by BB and SC based on a presentation at the 2019 Society for Healthcare Epidemiology Annual Meeting. All authors participated in abstracting data from included articles and manuscript review. MP led the analysis and manuscript preparation was completed by $\mathrm{BB}, \mathrm{SC}$ and MP.

Funding No funding was received for conducting this study. Access to REDCap software was provided through Institute for Clinical and Translational Science grant support (NIH and CTSA grant number: UL1TR002537) at the University of Iowa.

Data Availability Available upon request.

\section{Compliance with Ethical Standards}

Conflict of Interest The authors have no conflicts of interest to declare that are relevant to the content of this article.

Human and Animal Rights and Informed Consent This article does not contain any studies with human or animal subjects performed by any of the authors.

Ethics Approval This review was not considered to be human subject research.

Informed Consent Not applicable.

Consent to Participate Not applicable.

Consent for Publication Not applicable.

Code Availability Not applicable.

\section{References}

Papers of particular interest, published recently, have been highlighted as:

- Of importance

•- Of major importance

1. US Department of Health and Human Services. Office of Disease Prevention and Health Promotion. Health Care Associated Infections. HHS: National HAI Action Plan. National action plan to prevent health care-associated infections: road map to elimination [internet]. [cited: 24 Jul 2020]. Available from: https://health. gov/our-work/health-care-quality/health-care-associatedinfections/national-hai-action-plan.

2. Centers for Disease Control and Prevention (CDC). National healthcare safety network (NHSN) [internet]. [cited: 1 Nov 2019]; Available from: https://www.cdc.gov/nhsn/index. html.

3. Centers for Disease Control and Prevention (CDC): State-based HAI prevention activities [internet]. [cited: 9 Sept 2020]. Available from: https://www.cdc.gov/hai/state-based/index.html.

4. Stoessel K, Truscott W. National patient safety goal 7: recommendations for compliance [internet]. Infection Control Today: [cited: 
8 Jul 2009]. Available from: https://www.infectioncontroltoday. $\mathrm{com} / \mathrm{view} /$ national-patient-saf4)ety-goal-7-recommendationscompliance.

5. Medicare.gov. Hospital compare. Infections [internet]. [cited:10 Sept 2020]. Available from: https://www.medicare.gov/ hospitalcompare/Data/Healthcare-Associated-Infections.html.

6. Srinivasan A, Craig M, Cardo D. The power of policy change, federal collaboration, and state coordination in healthcareassociated infection prevention. Clin Infect Dis. 2012;55(3):42631. https://doi.org/10.1093/cid/cis407.

7. Pogorzelska-Maziarz M, de Cordova PB, Herzig C, Dick A, Reagan J, Stone PW. Perceived impact of state-mandated reporting on infection prevention and control departments [internet]. Am J Infect Control. 2019;47(2):118-22. https://doi.org/10. 1016/j.ajic.2018.08.012.

8. Agency for Healthcare Research and Quality (AHRQ). AHRQ's healthcare-associated infections program [internet]. Agency for Healthcare Research and Quality, Rockville, MD. 2019. Available from: https://www.ahrq.gov/hai/index.html. Accessed 20 Nov 2020.

9. Centers for Disease Control and Prevention (CDC): Data summary of HAIs in the US: assessing progress 2006-2016: a story of progress. [internet] Available from: https://www.cdc.gov/hai/data/ archive/data-summary-assessing-progress.html?CDC_AA refVal=https $\% 3$ A $\% 2$ F $\% 2$ Fwww.cdc.gov $\% 2$ Fhai $\%$ 2Fsurveillance $\% 2 \mathrm{~F}$ data-reports $\% 2 \mathrm{Fdata}$-summary-assessingprogress.html. Accessed 20 Nov 2020.

10. Poots AJ, Reed JE, Woodcock T, Bell D, Goldmann D. How to attribute causality in quality improvement: lessons from epidemiology. [internet]. BMJ Qual Saf. 2017;26(11):933-7. https://doi. org/10.1136/bmjqs-2017-006756.

11. Weaver SJ, Lubomksi LH, Wilson RF, Pfoh ER, Martinez KA, Dy SM. Promoting a culture of safety as a patient safety strategy: a systematic review. Ann Intern Med. 2013;158(5):369-74. https:// doi.org/10.7326/0003-4819-158-5-201303051-00002.

12. Singer SJ, Vogus TJ. Reducing hospital errors: interventions that build safety culture. Annu Rev Public Health. 2013;34(1):373-96.

13. Torben R. Organizational culture eats strategy for breakfast, lunch and dinner. [internet] 2014; Available from: https://www. torbenrick.eu/blog/culture/organisational-culture-eats-strategyfor-breakfast-lunch-anddinner/. Accessed 20 Nov 2020.

14. Melnyk BM. Making an evidence-based case for urgent action to address clinician burnout [internet]. AJAC@ [cited: 13 Jun 2019]. 2019;7(2):12-14. Available from: https://nam.edu/wp-content/ uploads/2019/09/American-Journal-of-Managed-Care-ClinicianBurnout-Article-Bern-Melnyk-June-2019.pdf.

15. National Academies of Sciences Engineering Medicine. Taking action against clinician burnout: a systems approach to professional well-being. The role of health care leadership [internet]. NAM. 2019; Available from: https://nam.edu/wp-content/uploads/2019/ 12/CR-report-leadership-brief-final.pdf. Accessed 20 Nov 2020.

16. American Medical Association. AMA Joy in medicine recognition program. Chicago, IL [internet]. AMA. 2020. Available from: https://www.ama-assn.org/system/files/2020-04/joy-awardbrochure.pdf. Accessed 20 Nov 2020.

17. American Nurses Association. Healthy work environment [internet]. ANA. [cited: 24 May 2019]. Available from: https://www. nursingworld.org/practice-policy/work-environment/healthsafety/culture-of-safety/.

18. Leonard M, Frankel A. How can leaders influence a safety culture [internet]. The Health Foundation; May 2012 [cited: 10 Sept 2020]. Available from: https://www.health.org.uk/sites/ default/files/HowCanLeadersInfluenceASafetyCulture.pdf.

19. Sexton JB, Adair KC, Leonard MW, Frankel TC, Proulx J, Watson SR, et al. Providing feedback following leadership walk rounds is associated with better patient safety culture, higher employee engagement and lower burnout. [internet]. BMJ Qual Saf. 2018;27(4):261-70. https://doi.org/10.1136/bmjqs-2016006399.

20. Emergency Care Research Institute (ECRI). Culture of safety: an overview [internet]. Healthcare Risk Control. 14 Jun 2019. Available from: https://www.ecri.org/components/HRC/Pages/ RiskQual21.aspx.

21. Joint Commission. The essential role of leadership in developing a safety culture [internet]. Sentinel Alert Event. [cited: 1 Mar 2017];57. Available from: https://www.jointcommission.org/-/ media/tjc/documents/resources/patient-safety-topics/sentinelevent/sea_57_safety_culture_leadership_0317pdf.pdf.

22. Agency for Healthcare Research and Quality (AHRQ). Culture of safety [internet]. In: Patient Safety Network. [cited: 7 Sept 2019]. Available from: https://psnet.ahrq.gov/primer/culture-safety.

23. Schein EH. Organizational culture and leadership. 4th ed. San Francisco: EH Schein; 2010. 464 p.

24. Joint Commission. Improving patient and worker safety: opportunities for synergy, collaboration and innovation [internet]. 2012 [cited: 10 Sept 2020]. Available from: https://www. jointcommission.org/-/media/deprecated-unorganized/importedas sets/tjc/system-folders/topics-library/tjcimprovingpatientandworkersafety-monographpdf.pdf?db= web\&hash=2772E4D4E100BCE47F731AA1F39471A4.

25. Stone PW, Hughes R, Dailey M. Creating a safe and high-quality health care environment [internet]. In: Hughes RG, editor. Patient safety and quality: an evidence-based handbook for nurses, vol. 21. Rockville: AHRQ (US); 2008. Available from: https://www. ncbi.nlm.nih.gov/books/NBK2634. Accessed 20 Nov 2020.

26. Gershon RRM, Stone PW, Bakken S, Larson E. Measurement of organizational culture and climate in healthcare. J Nurs Adm. 2004;34(2):33-40.

27. Joint Commission. 2020 Comprehensive accreditation manual for hospitals. 15 Nov 2019.

28. National Quality Forum Safe Practices Consensus Committee. Safe practices for better healthcare-2010 update: a consensus report [internet]. NQF [cited: Apr 2010];1-446. Available from: http://www.quality forum.org/Publications/2010/04/Safe Practices_for_Better_Healthcare_\%E2\%80\%93_2010_Update. aspx.

29. Leapfrog Group. Raising the bar for safer health care. Building a movement for transparency [internet]. [cited: 3 Sept 2020]. Available from: https://www.leapfroggroup.org/about.

30. Agency for Healthcare Research and Quality (AHRQ). 10 patient safety tips for hospitals [internet]. Patient Safety Network. 29 Nov 2006. Available from: https://www.psnet.ahrq.gov/issue/10patient-safety-tips-hospitals. Accessed 20 Nov 2020.

31. National Steering Committee for Patient Safety. Self-assessment tool: a national action plan to advance patient safety [internet]. Boston, Massachusetts: Institute for Healthcare Improvement. 2020. Available from: http://www.ihi.org/Engage/Initiatives/ National-Steering-Committee-Patient-Safety/Pages/NationalAction-Plan-to-Advance-Patient-Safety.aspx. Accessed 20 Nov 2020.

32. Donabedian A. Evaluating the quality of medical care. The Milbank Quarterly. 2005;83(4):691-729.

33. Pronovost P, Needham D, Berenholtz S, Sinopoli D, Chu H, Cosgrove $\mathrm{S}$, et al. An intervention to decrease catheter-related bloodstream infections in the ICU. N Engl J Med. 2006;355(26): 2725-32.

34. Agency for Healthcare Research and Quality (AHRQ). Healthcare-Associated Infections Program. The CUSP method [internet]. 2019. Available from: https://www.ahrq.gov/hai/cusp/ index.html. Accessed 20 Nov 2020.

35. Braithwaite J, Herkes J, Ludlow K, Testa L, Lamprell G. Association between organizational and workplace cultures, and 
patient outcomes: systematic review. BMJ Open. 2017;7(11): e017708.

36. DeJoy DM. Behavior change versus culture change: divergent approaches to managing workplace safety. Saf Sci. 2005;43: 105-29.

37. Gardam M, Reason P, Gitterman L. Healthcare associated infections: new initiatives and continuing challenges. Healthcare quarterly special issue sixth in a series papers patient safety. Johnson Johnson Med Co. 2012;15(6):36-41.

38. Clancy CM. New research highlights the role of patient safety culture and safer care. J Nurs Care Qual. 2011;26(3):193-6.

39. American College of Healthcare Executives and IHI/NPSF Lucian Leape Institute. Leading a culture of safety: a blueprint for success [internet]. American College of Healthcare Executives and Institute for Healthcare Improvement. 2017; Available from: http://safety.ache.org. Accessed 20 Nov 2020.

40. Ginsburgh L, Gilin D, Tregunno D, Norton PG, Flemons W, Fleming M. Advancing measurement of patient safety culture HSR. Health Serv Res. 2009;44:1.

41. Hodgen A, Ellis L, Churruca K, Bierbaum M. Safety culture assessment in health care: a review of the literature on safety culture assessment modes. ACSQHC: Sydney; 2017.

42. Hessels A, Larson E. The relationship between patient safety climate and standard precaution adherence: a systematic review of the literature. [internet]. J Hosp Infect. 2016;92(4):349-62. https:// doi.org/10.1016/j.jhin.2015.08.023.

43.• van Buijtene A, Foster D. Does a hospital culture influence adherence to infection prevention and control and rates of healthcare associated infection? A literature review. J Infect Prev. 2019;20(1):5-17.

44.• De Bono S, Heling G, Borg MA. Organizational culture and its implications for infection prevention and control in healthcare institutions. J Hosp Infect. 2014;86(1):1-6.

45. Alsalem G, Bowie P, Morrison J. Assessing safety climate in acute hospital settings: a systematic review of the adequacy of the psychometric properties of survey measurement tools. [internet]. BMC Health Serv Res. 2018;18:353. https://doi.org/10.1186/ s12913-018-3167-x.

46. Szymczak JE. Infections and interaction rituals in the organization: clinician accounts of speaking up or remaining silent in the face of threats to patient safety. [internet]. Sociol Health Illn. 2016;38(2):325-39. https://doi.org/10.1111/1467-9566.12371.

47. Weaver SJ, Weeks K, Pham JC, Pronovost PJ. On the CUSP: stop BSI: evaluating the relationship between central line-associated bloodstream infection rate and patient safety climate profile. Am J Infect Control. 2014;42(10 Suppl):S203-8.

48. Ginsburgh L, Oore DG. Patient safety climate strength: a concept that requires more attention. [internet]. BMJ Qual Saf. 2016;25(9): 680-7. https://doi.org/10.1136/bmjqs-2015-00415053.

49. Joint Commission. Measuring hand hygiene adherence: overcoming the challenges. [internet]. 2009. Available from: https://www. jointcommission.org/-/media/deprecated-unorganized/importedassets/tjc/system-folders/topics-library/hh_monographpdf.pdf? $\mathrm{db}=$ web\&hash=7F1A70731D44DC2D183B1038CE34EC46. Accessed 20 Nov 2020.

50. Haraden C. What is a bundle? IHI. 2020. Available from: http:// www.ihi.org/resources/Pages/ImprovementStories/ WhatIsaBundle.aspx. Accessed 20 Nov 2020.

51. Wright MO, Allen-Bridson K, Hebden JN. Assessment of the accuracy and consistency in the application of standardized surveillance definitions: a summary of the American Journal of Infection Control and National Healthcare Safety Network case studies, 2010-2016. Am J Infect Control. 2017;45(6):607-11. https://doi.org/10.1016/j.ajic.2017.03.035.

52. Rodríguez-Acelas AL, de Abreu AM, Engelman B, CañonMontañez W. Risk factors for health care-associated infection in hospitalized adults: systematic review and meta-analysis. [internet]. Am J Infect Control. 2017;45(12):e149-56. https://doi.org/ 10.1016/j.ajic.2017.08.016.

53. Eccles M, Grimshaw J, Campbell M, Ramsay C. Research designs for studies evaluating the effectiveness of change and improvement strategies. Qual Saf Health Care. 2003;12(1):47-52.

54. Knudsen SV, Laursen HVB, Johnsen SP, Bartels PD, Ehlers LH. Mainz, J. can quality improvement improve the quality of care: a systematic review of reported effects and methodological rigor in plan-do-study-act projects. [internet]. BMC Health Serv Res. 2019;19:683. https://doi.org/10.1186/s12913-019-4482-6.

55. Hirschhorn LR, Ramaswamy R, Devnani M, Wandersman A, Simpson LA, Garcia-Elorrio E. Research versus practice in quality improvement? Understanding how we can bridge the gap. Int J Qual Health Care. 2018;30(1):24-8.

56. Hsu YJ, Kosinski AS, Wallace AS, Saha-Chaudhuri P, Chang $\mathrm{BH}$, Speck K, et al. Using a society database to evaluate a patient safety collaborative: the cardiovascular surgical translational study. [internet]. J Comp Eff Res. 2019;8(1):21-32. https://doi. org/10.2217/cer-2018-0051.

57. Itri JN, Bakow E, Probyn L, Kadom N, Duong PT, Gettle LM, et al. The science of quality improvement. Acad Radiol. 2017;24(3):253-62.

58. Finkelstein JA, Brickman AL, Capron A, Ford DE, Gombosev A, Greene SM, et al. Oversight on the borderline: quality improvement and pragmatic research [internet]. Clin Trials. 2015;12(5): 457-66. https://doi.org/10.1177/1740774515597682.

59. Harris PA, Taylor R, Thielke R, Payne J, Gonzalez N, Conde JG. Research electronic data capture (REDCap)-a metadata-driven methodology and workflow process for providing translational research informatics support. J Biomed Inform. 2009;42(2):37781.

60. Harris PA, Taylor R, Minor BL, Elliott V, Fernandez M, O’Neal L, et al. REDCap Consortium, The REDCap consortium: building an international community of software partners [internet]. J Biomed Inform. 2019. https://doi.org/10.1016/j.jbi.2019.103208.

61. Hsu YJ, Marsteller JA. Influence of the comprehensive unit-based safety program in ICUs: evidence from the keystone ICU project. [internet]. 2016, 2015;31(4):349-57. https://doi.org/10.1177/ 1062860615571963.

62. Berenholtz SM, Pham JC, Thompson DA, Needham DM, Lubomski LH, Hyzy RC, et al. Collaborative cohort study of an intervention to reduce ventilator-associated pneumonia in the intensive care unit. [internet]. Infect Control Hosp Epidemiol. 2011;32(4):305-14 Available from: https://pubmed.ncbi.nlm. nih.gov/21460481/. Accessed 20 Nov 2020.

63. Jain R, Kralovic SM, Evans ME, Ambrose M, Simbartl LA, Obrosky DS, et al. Veterans affairs initiative to prevent methicillin-resistant staphylococcus aureus infections. N Engl J Med. 2011;364(15):1419-30.

64. Hessels AJ, Genovese-Schek V, Agarwal M, Wurmser T, Larson EL. Relationship between patient safety climate and adherence to standard precautions. Am J Infect Control. 2016;44(10):1128-32. https://doi.org/10.1016/j.ajic.2016.03.060.

65. Braddock CH, Szaflarski N, Forsey L, Abel L, HernandezBoussard T, Morton J. The TRANSFORM patient safety project: a microsystem approach to improving outcomes on inpatient units [internet]. J Gen Intern Med. 2015;30(4):425-33. https://doi.org/ 10.1007/s11606-014-3067-7.

66. Chang BH, Hsu YJ, Rosen M, Gurses AP, Huang S, Xie A, et al. Reducing three infections across cardiac surgery programs: a multisite cross-unit collaboration [internet]. Am J Med Qual. 2020;35(1):37-45. https://doi.org/10.1177/1062860619845494.

67. Fan CJ, Pawlik TM, Daniels T, Vernon N, Banks K, Westby P, et al. Association of safety culture with surgical site infection 
outcomes [internet]. J Am Coll Surg. 2016;222(2):122-8. https:// doi.org/10.1016/j.jamcollsurg.2015.11.008.

68. Meddings J, Reichert H, Greene MT, Safdar N, Krein SL, Olmsted RN, et al. Evaluation of the association between hospital survey on patient safety culture (HSOPS) measures and catheterassociated infections: results of two national collaboratives. [internet]. BMJ Qual Saf. 2017;26:226-35. https://doi.org/10.1136/ bmjqs-2015-005012.

69. Richter JP, McAlearney AS. Targeted implementation of the comprehensive unit-based safety program through an assessment of safety culture to minimize central line-associated bloodstream infections [internet]. Health Care Manage [cited: Jan/Mar 2018];43(1):42-49. Available from: https://pubmed.ncbi.nlm. nih.gov/27529403/.

70. Sakowski JA, Hooper L, Holton T, Brody AA. Partners advancing clinical excellence: building professional councils for quality improvement at six community hospitals. Creat Nurs. 2012;18(4): $177-86$.

71. Smith SA, Yount N, Sorra J. Exploring relationships between hospital patient safety culture and consumer reports safety scores. [internet]. BMC Health Serv Res. 2017;17:143. https://doi.org/10. 1186/s12913-017-2078-6.

72. Choi SW, Chang L, Hanauer DA, Shaffer-Hartman J, Teitelbaum D, Lewis I, et al. Rapid reduction of central line infections in hospitalized pediatric oncology patients through simple quality improvement methods. [internet]. Pediatr Blood Cancer. 2013;60(2):262-9. https://doi.org/10.1002/pbc.24187.

73. Lin DM, Carson KA, Lubomski LH, Wick EC, Cuong J. Statewide collaborative to reduce surgical site infections: results of the Hawaii surgical unit-based safety program [internet]. J Am Coll Surg; 1 Aug 2018 [cited: 18 May 2018]. 227(2):189-197.E1. Available from: https://www.journalacs.org/article/S10727515(18)30330-2/fulltext

74. Mayer CM, Cluff L, Lin W-T, Willis TS, Stafford RE, Williams $\mathrm{C}$, et al. Evaluating efforts to optimize TeamSTEPPS implementation in surgical and pediatric intensive care units. Jt Comm J Qual Patient Saf. 2011;37(8):365-AP3.

75. Millson T, Hackbarth D, Bernard HL. A demonstration project on the impact of safety culture on infection control practices hemodialysis. [internet]. Am J Infect Control. 2019;47(9):1122-9. https://doi.org/10.1016/j.ajic.2019.02.026.

76. Thomas-Hawkins C, Flynn L. Patient safety culture and nursereported adverse events in outpatient hemodialysis units [internet]. Res Theory Nurs Pract Int J. 2015;29(1):53-65. https://doi.org/10. 1891/1541-6577.29.1.53.

77. Sreeramoju P, Dura L, Fernandez ME, Minhajuddin A, Simacek $\mathrm{K}$, Fomby TB, et al. Using a positive deviance approach to influence the culture of patient safety related to infection prevention. [internet]. Open Forum Infect Dis. 2018;5(10):ofy231. https://doi. org/10.1093/ofid/ofy231

78. Rawat N, Yang T, Ali KJ, Catanzaro M, Cohen MD, Farley DO, et al. Two-state collaborative study of a multifaceted intervention to decrease ventilator-associated events. [internet]. Crit Care Med. 2017;45(7):1208-15. https://doi.org/10.1097/CCM. 0000000000002463 .

79. Abusalem S, Polivka B, Coty MB, Crawford TN, Furman CD, Alaradi M. The relationship between culture of safety and rate of adverse events in long-term care facilities. J Patient Saf. 2019. https://doi.org/10.1097/PTS.0000000000000587.

80. Smith SN, Greene MT, Mody L, Banaszak-Holl J, Peterson LD, Meddings J. Evaluation of the association between nursing home survey on patient safety culture (NHSOPS) measures and catheterassociated urinary tract infections: results of a national collaborative. BMJ Qual Saf. 2018;27:464-73.

81. Daugherty EL, Paine LA, Maragakis LL, Sexton JB, Rand CS. Safety culture and hand hygiene: linking attitudes to behavior. [internet]. Infect Control Hosp Epidemiol. 2012;33(12):1280-2 Available from: http://www.jstor.org/stable/10.1086/668432. Accessed 20 Nov 2020.

82. Hsu YJ, Marsteller JA. Who applies an intervention to influence cultural attributes in a quality improvement collaborative? J Patient Saf. 2015;16(1):1-6 Available from: https://pubmed.ncbi. nlm.nih.gov/26164707/. Accessed 20 Nov 2020.

83. Meeks DW, Lally KP, Carrick MM, Lew DF, Thomas EJ, Doyle $\mathrm{PD}$, et al. Compliance with guidelines to prevent surgical site infections: as simple as 1-2-3. [internet]. Am J Surg. 2011;201(1):76-83. https://doi.org/10.1016/j.amjsurg.2009.07. 050.

84. Profit J, Sharek PJ, Kan P, Rigdon J, Desai M, Nisbet CC, et al. Teamwork in the NICU setting and its association with healthcareassociated infections in very low birth weight infants. [internet]. Am J Perinatol. 2017;34(10):1032-40. https://doi.org/10.1055/s0037-1601563.

85. Profit J, Sharek PJ, Cui X, Nisbet CC, Thomas EJ, Tawfik DS, et al. The correlation between NICU safety culture and quality of care. J Patient Saf. 2020;2018(7):1-21 Available from: https:// pubmed.ncbi.nlm.nih.gov/30407963/. Accessed 20 Nov 2020.

86. Vigorito MC, McNicoll L, Adams L, Sexton B. Improving safety culture results in Rhode Island ICUs: lessons learned from the development of action-oriented plans. Jt Comm J Qual Saf. 2011;37(11):509-14 AP1.

87. Brilli RJ, McClead RE, Crandall WV, Stoverock L, Berry JC, Wheeler TA. A comprehensive patient safety program can significantly reduce preventable harm, associated costs, and hospital mortality. J Pediatr Dec. 2013;163(6):1638-45.

88. Southworth SL, Henman LJ, Kinder LA, Sell JL. The journey to zero central catheter-associated bloodstream infections: culture change in an intensive care unit. Crit Care Nurse. 2012;32(2): 49-54.

89. Miller MA, Krein SL, Saint S, Kahn JM, Iwashyna TJ. Organizational characteristics associated with the use of daily interruption of sedation in US hospitals: a national study. BMJ Qual Saf. 2012;21(2):145-51.

90. Pronovost PJ, Marsteller JA, Goeschel CA. Preventing bloodstream infections: a measurable national success story in quality improvement. Health Aff (Millwood). 2011;30(4):628-34.

91. Nelson S, Stone PW, Jordan S, Pogorzelska M, Halpin H, Vanneman M, et al. Patient safety climate: variation in perceptions by infection preventionists and quality directors. Interdiscip Perspect Infect Dis. 2011;2011:357121.

92. Pogorzelska-Maziarz M, Nembhard IM, Schnall R, Nelson S, Stone PW. Psychometric evaluation of an instrument for measuring organizational climate for quality: evidence from a national sample of infection preventionists. [internet]. Am J Med Qual. 2016;31(5):441-7. https://doi.org/10.1177/1062860615587322.

93. Gilmartin HM, Sousa KH. Testing the quality health outcomes model applied to infection prevention in hospitals. [internet]. Qual Manag health care. 2016;25(3):149-61. https://doi.org/10. 1097/QMH.0000000000000102.

94. Kelly D, Kutney-Lee A, Lake ET, Aiken LH. The critical care work environment and nurse-reported health care-associated infections. Am J Crit Care. 2013;22(6):482-8.

95. Garland KV. A survey of United States dental hygienists' knowledge, attitudes, and practices with infection control guidelines. J Dent Hyg. 2013;87(3):140-51.

96. Yanke E, Moriarty H, Carayon P, Safdar N. A qualitative, interprofessional analysis of barriers to and facilitators of implementation of the Department of Veterans Affairs' Clostridium difficile prevention bundle using a human factors engineering approach. Am J Infect Control. 2018;46(3):276-84. https://doi.org/10.1016/ j.ajic.2017.08.027. 
97. Sinkowitz-Cochran RL, Burkitt KH, Cuerdon T, Harrison C, Gao $\mathrm{S}$, Obrosky DS, et al. The associations between organizational culture and knowledge, attitudes, and practices in a multicenter veterans affairs quality improvement initiative to prevent methicillin-resistant Staphylococcus aureus. Am J Infect Control. 2012;40:138-43.

98. Talbot TR, Johnson JG, Fergus C, Domenico JH, Schaffner W, Daniels TL, et al. Sustained improvement in hand hygiene adherence: utilizing shared accountability and financial incentives. Infect Control Hosp Epidemiol. 2013;34(11):1129-36.

99. Lyles RD, Moore NM, Weiner SB, Sikka M, Lin MY, Weinstein RA, et al. Understanding staff perceptions about klebsiella pneumoniae carbapenemase-producing Enterobacteriaceae control efforts in Chicago long-term acute care hospitals [internet]. Infect Control Hosp Epidemiol. 2014;35(4):367-74. https://doi. org/10.1086/675596.

100. Robbins J, McAlearney AS. Encouraging employees to speak up to prevent infections: opportunities to leverage quality improvement and care management processes. Am J Infect Control. 2016;44(11):1224-30. https://doi.org/10.1016/j.ajic.2016.03.007.

101. Harnage S. Seven years of zero central-line associated bloodstream infections. Br J Nurs. 2012;21(21):S6-S12.

102. Miller K, Briody C, Casey D, Kane JK, Mitchell D, Patel B, et al. Using the comprehensive unit-based safety program model for sustained reduction in hospital infections. Am J Infect Control. 2016:44:969-76.

103. Phipps AR, Paradis M, Peterson KA, Jensen J, Nielsen K, Hall M, et al. Reducing serious safety events and priority hospital-acquired conditions in a pediatric hospital with the implementation of a patient safety program. The Joint Commission. 2018;44:334-40.

104. Wick EC, Galante DJ, Hobson DB, Benson AR, Lee K, Berenholtz SM, et al. Organizational culture changes result in improvement in patient-centered outcomes: implementation of an integrated recovery pathway for surgical patients [internet]. J Am Coll Surg. 2015;221(3):669-77. https://doi.org/10.1016/j. jamcollsurg.2015.05.008.

105. DePalo VA, McNicoll L, Cornell M, Rocha MC, Adams L, Pronovost PJ. The Rhode Island ICU collaborative: a model for reducing central line-associated bloodstream infection and ventilator-associated pneumonia statewide [internet]. Qual Saf Health Care. 2010;19:555-61. https://doi.org/10.1136/qshc. 2009.038265.

106. Joyce JS, Cioffi GA, Petriwsky JG, Robinson JS. Legacy Health's 'Big Aims' initiative to improve patient safety reduced rates of infection and mortality among patients. Health Aff (Millwood). 2011;30(4):619-27.

107. Medina A, Serratt T, Pelter M, Brancamp T. Decreasing central line-associated bloodstream infections in the non-ICU population. J Nurs Care Qual. 2014;29(2):133-40.

108. Robinson C, Hevener S, Hoze M, Nichols AA. Ventilatorassociated pneumonia patients in the intensive care unit. JONA. 2018;48(2):79-84.

109. Rosenberg RE, Devins L, Geraghty G, Bock S, Dugan CA, Transou M, et al. Engaging frontline staff in central lineassociated bloodstream infection prevention practice in the wake of superstorm Sandy. The Joint Commission. 2015;41(10):462-8 AP1.

110. Cumbler E, Castillo L, Satorie L, Ford D, Hagman J, Hodge T, et al. Culture change in infection control. Applying psychological principles to improve hand hygiene. J Nurs Care Qual. 2013;28(4):304-11.

111. Day C. Engaging the nursing workforce. An evidence-based tool kit. Nurs Adm Q. 2009;33(3):238-44.

112. Foulk KC, Tocydlowski P, Snow TM, McCloud K, Cuevas M, Bishop D, et al. Infusing fun into quality and safety initiatives. Nurs. 2012:14-6.

113. Johnson L, Grueber S, Schlotzhauer C, Phillips E, Bullock P, Basnett J, et al. A multifactorial action plan improves hand hygiene adherence and significantly reduces central line-associated bloodstream infections. Am J Infect Control. 2014;42:1146-51.

114. Raveis VH, Conway LJ, Uchida M, Pogorzelska-Maziarz M, Larson EL, Stone PW. Translating infection control guidelines into practice: implementation process within a health care institution. Qual Health Res. 2014;24(4):551-60.

115. Campione JR, Yount ND, Sorra J. Questions regarding the authors' conclusions about the lack of change in hospital survey on patient safety culture (HSOPS) scores related to reduction of hospital-acquired infections [internet]. BMJ Qual Saf. 2018;27: e3 Available from: 1136/bmjqs-2017-007360.

116. Borg MA, Camilleri L, Waisfisz B. Understanding the epidemiology of MRSA in Europe: do we need to think outside the box? J Hosp Infect. 2012;81:251e256.

117. Su G. A collaborative approach to reduce healthcare-associated infections. Br J Nurs. 2016;25:582-6.

Publisher's Note Springer Nature remains neutral with regard to jurisdictional claims in published maps and institutional affiliations. 